\title{
Loss of TET proteins in regulatory T cells unleashes effector function
}

Xiaojing Yue ${ }^{1}$, Chan-Wang J. Lio ${ }^{1}$, Daniela Samaniego-Castruita ${ }^{1}$, Xiang Li ${ }^{1}$, Anjana Rao ${ }^{1,2,3 *}$

${ }^{1}$ Division of Signaling and Gene Expression, La Jolla Institute for Allergy \& Immunology, La Jolla, California, 92037, USA.

${ }^{2}$ Sanford Consortium for Regenerative Medicine, La Jolla, California, 92037, USA.

${ }^{3}$ Department of Pharmacology and Moores Cancer Center, University of California, San Diego, La Jolla, California, 92093.

* Correspondence: arao@lji.org (A.R.) 


\section{Abstract}

TET enzymes oxidize 5-methylcytosine $(5 \mathrm{mC})$ to 5-hydroxymethylcytosine $(5 \mathrm{hmC})$ and other oxidized methylcytosines, mediating DNA demethylation and serving as new epigenetic marks. Here we examine the role of TET proteins in Foxp3 ${ }^{+}$regulatory $\mathrm{T}$ (Treg) cells, a distinct lineage of $\mathrm{CD4}^{+} \mathrm{T}$ cells that prevent autoimmunity and maintain immune homeostasis. We report that Tet2/3 ${ }^{\text {fl/fI}}$ Foxp $3^{\text {Cre }}$ mice that lack Tet2 and Tet3 specifically in Treg cells develop splenomegaly, leukocyte infiltration into tissues and inflammatory disease. Treg cells from these mice showed altered expression of Treg signature genes, with upregulation of genes involved in cell cycle regulation, DNA damage repair and cancer. In littermate mice with more severe inflammation, both $\mathrm{CD}^{+}{ }^{+} \mathrm{Foxp}^{+}$and $\mathrm{CD4}^{+}$Foxp3 $^{-}$cells showed strong skewing towards Tfh and/or Th17 phenotypes. Notably, the presence of wild type Treg cells in mixed bone marrow chimeras and Tet2/3/f/fl$F o x p 3^{W T / C r e}$ heterozygous female mice did not suppress the aberrant phenotype and function of Tet $2 / 3^{f / f l} F o x p 3^{\text {Cre }}$ Treg cells. Fate-mapping experiments indicated that Treg cells from Tet2/3 ${ }^{f / f l} F o x p 3^{C r e}$ mice were more prone to lose Foxp3 expression; moreover, transfer of total $\mathrm{CD}^{+} \mathrm{T}$ cells isolated from Tet $2 / 3^{f / f l}$ Foxp $3^{\text {Cre }}$ mice could elicit inflammatory disease in fully immunocompetent mice. Together, these data indicate that Tet2 and Tet3 are guardians of Treg cell stability and immune homeostasis in mice. 


\section{Introduction}

Regulatory $\mathrm{T}$ (Treg) cells are a distinct lineage of $\mathrm{CD}^{+} \mathrm{T}$ lymphocytes that prevent autoimmunity against self-antigens and maintain immune homeostasis 1,2. The lineage specification, development and suppressive function of Treg cells are controlled by Foxp3, an X-chromosome-encoded transcription factor that is the most specific marker distinguishing Treg cells from other $T$ helper cell populations ${ }^{3}$. Foxp3-expressing Treg cells have been reported to be stable in both steady state and inflammatory conditions in vivo ${ }^{4}$, but a fraction of Treg cells show unstable Foxp3 expression ${ }^{5,6}$. Fate mapping experiments have shown that many of these Treg cells are "ex-Treg" cells that derive from Foxp3-expressing Treg cells that subsequently lose Foxp3 expression ${ }^{5}$, but some may be conventional $\mathrm{T}$ cells that transiently express Foxp3, thus representing a minor population of uncommitted Treg cells ${ }^{6}$. Moreover, Treg-specific genetic ablation of many gene products including cell surface proteins such as neuropilin1, transcription factors such as $\mathrm{Nr} 4 \mathrm{a}$, signaling molecules such as Pten, and epigenetic regulators such as Ezh2 - results in instability of Treg Foxp3 expression and/or loss of suppressive function $7,8,9,10,11$.

Epigenetic changes, including histone modifications, DNA methylation and chromatin accessibility, play a critical role in establishing and maintaining the Treg cell lineage ${ }^{3}$. The best studied of these epigenetic changes is DNA demethylation at various Treg-specific demethylated regions (TSDRs), including two "conserved non-coding sequences" (CNS) CNS1 and CNS2 within the Foxp3 locus ${ }^{12,13}$. The stability of Foxp3 expression is closely linked to the demethylated status of CNS1 and CNS2 ${ }^{12,13}$, while Treg-specific gene expression and optimal Treg function are linked to the DNA methylation status of other relevant TSDRs. Thus, it is important to understand how DNA methylation is regulated at these elements, and how it in turn controls the stability and function of Treg cells.

TET family proteins are $\mathrm{Fe}(\mathrm{II})$ and 2-oxoglutarate-dependent dioxygenases that catalyze oxidation of the methyl group of 5-methylcytosine $(5 \mathrm{mC})$ in DNA to 5-hydroxymethylcytosine (5hmC) and the further oxidized products 5-formylcytosine $(5 \mathrm{fC})$ and 5-carboxylcytosine $(5 \mathrm{caC}){ }^{14,15,16,17,18}$. These modified bases are intermediates in DNA demethylation as well as potential epigenetic marks that are capable of recruiting specific readers to exert specific functions ${ }^{19,20,21}$. Recent studies on the role of TET proteins in the immune and hematopoietic systems have revealed a profound influence of TET proteins and DNA modification on immune/ hematopoietic cell development and function. Acute elimination of TET function by deletion of both Tet2 and Tet3 in hematopoietic stem cells induced the rapid development of an aggressive and fully-penetrant myeloid leukaemia in adult mice ${ }^{22}$. Concomitant deletion of Tet2 and Tet3 by Mb1-Cre in early B cells resulted in developmental blockade at the pro-B to pre-B cell transition due to a defect in immunoglobulin light chain rearrangement ${ }^{23,24}$. Deletion of Tet2 and Tet3 in $\mathrm{T}$ cells mediated by $C D 4-C r e$ led to an antigen-driven expansion of invariant NKT (iNKT) cells, which developed rapidly into CD1d-restricted iNKT cell lymphoma ${ }^{25}$. Treg cells in this Tet2/3-deficient mouse strain displayed unstable Foxp3 expression, concomitantly with DNA hypermethylation at CNS1, CNS2, and other TSDRs ${ }^{12}$. Combined deletion of Tet1 and Tet2 also resulted in CNS2 hypermethylation and impaired Treg cell differentiation and function ${ }^{26}$.

Our previous study on the role of TET proteins in Treg cells ${ }^{12}$ was complicated by the iNKT cell expansion occurring in the same mouse strain, in which Tet gene deletion was mediated by CD4-Cre ${ }^{12,25}$. In our current study, we used a mouse strain in which Tet2 and Tet3 deficiency were targeted specifically to Foxp3-expressing Treg cells using Foxp $3^{\text {YFP-Cre }}\left(\right.$ Foxp $3^{\text {Cre }}$ ). Here we show that Tet2/3 $3^{f / f l}$ Foxp $3^{\text {Cre }}$ mice develop an inflammatory disease with splenomegaly and leukocyte infiltration into lung, and that CD4 ${ }^{+}$Foxp $3^{+}$Treg cells, CD4 ${ }^{+}$Foxp3 $3^{-}$and $\mathrm{CD}^{+} \mathrm{T}$ cells in these mice display an activated phenotype. Transcriptome analysis showed dysregulation of Treg signature genes as well as genes related to cell cycle, DNA damage repair and cancer in Tet2/3 DKO Treg cells compared to WT Treg cells. Perplexingly, however, a very similar inflammatory disease developed in Tet2/3 ${ }^{f / f l} F o x p 3^{W T / C r e}$ heterozygous female mice, as well as in mixed bone marrow chimeras in which lethally irradiated mice were reconstituted with a 1:1 mixture of wildtype and 
Tet2/3 $3^{f / f l}$ Foxp $3^{\text {Cre }}$ bone marrow cells, indicating that the presence of wildtype (WT) Treg cells was not sufficient to suppress the inflammatory phenotype observed in Tet2/3 DKO mice. Fate-mapping experiments showed that Treg cells from Tet2/3//fl Foxp $3^{\text {Cre }}$ DKO mice were more prone to lose Foxp3 expression and become "exTreg" cells. Furthermore, transfer of total CD4 ${ }^{+} \mathrm{T}$ cells from Tet2/3 ${ }^{f / f t} F o x p 3^{C r e}$ DKO mice, which contained these ex-Treg cells, elicited inflammatory disease in immunocompetent mice. Thus TET deficiency in Treg cells resulted in a dominant inflammatory disease, in which the inflammatory phenotype was driven, at least in part, by ex-Treg cells that acquired effector function, and also conferred inflammatory function on endogenous host $\mathrm{CD}^{+} \mathrm{T}$ cells. Overall, our data indicate that Tet2 and Tet3 are essential for maintenance of Treg cell stability and immune homeostasis in mice.

\section{Results}

\section{Uncontrolled $\mathrm{T}$ cell activation and tissue infiltration in mice lacking Tet2 and Tet3 in Treg cells}

To investigate the role of TET proteins in Treg cells, we crossed mice carrying LoxP-flanked Tet2 and Tet3 alleles $\left(\right.$ Tet2/3 $\left.3^{\text {fl/fl}}\right)$ with Foxp3 $3^{\text {YFP-Cre }}\left(\right.$ Foxp $\left.3^{\text {Cre }}\right)$ mice in which a YFP-Cre fusion protein is knocked into the 3' UTR of the Foxp3 gene ${ }^{27}$, to generate mice with Treg-specific deletion of Tet2 and Tet3 (Tet2/3 ${ }^{f / f t}$ Foxp3 ${ }^{\text {Cre }}$ mice). Tet2 and Tet3 mRNAs were specifically deleted in $\mathrm{CD}^{+}{ }^{+} \mathrm{YFP}^{+}$Treg cells but not in CD4 ${ }^{+} \mathrm{YFP}^{-}$ conventional T cells (Supplementary Fig. 1a). Mice lacking Tet2 and Tet3 in Treg cells did not survive past 822 weeks of age (Fig. 1a), although a fraction of male mice survived slightly longer than female mice (Supplementary Fig. 1b). Tet2/3/flfl Foxp3 ${ }^{\text {Cre }}$ mice displayed splenomegaly and lymphadenopathy, primarily of mesenteric lymph nodes ( $\mathrm{mLN}$, Supplementary Fig. 1c), as evidenced by an increased cellularity (Fig. 1b). The slight increase in cellularity observed in peripheral lymph nodes ( $p L N)$ did not reach statistical significance (Fig. 1b). Histological analysis revealed disrupted splenic architecture in Tet2/3 ${ }^{\text {fl/fl}}$ Foxp $3^{\mathrm{Cre}}$ mice with expansion of the white pulp areas, accompanied by leukocyte infiltration into the lung (Supplementary Fig. 1d). Examination of the peripheral blood showed an increase in neutrophils and a decrease in lymphocytes, which were within the normal range (Table S1). The concentration of red blood cells appeared normal (Table S1). Tet2/3 ${ }^{f / f l} F o x p 3^{C r e}$ mice had significantly higher titers of anti-dsDNA antibodies in the serum compared to WT mice (Supplementary Fig. 2a), suggesting altered self-tolerance. In addition, the titer of serum IgG2b isotype was significantly higher in Tet2/3 ${ }^{f / f l} F o x p 3^{C r e}$ mice than in WT mice, and there was a tendency towards increased titers of serum $\lg G 1$, $\lg G 2 a, \lg G 3$ and $\lg \mathrm{M}$, which correlated with the severity of disease development in the mice. In contrast, the titer of serum IgA appeared slightly decreased in Tet2/3 $3^{f / f l}$ Foxp $3^{\text {Cre }}$ mice compared to WT mice (Supplementary Fig. 2b).

Tet2/3 $3^{f / f l}$ Foxp3 ${ }^{\text {Cre }}$ mice displayed a significant reduction in the percentages of CD4 ${ }^{+}$and $\mathrm{CD}^{+} \mathrm{T}$ cells in spleen and peripheral lymph nodes (Fig. 1c, left panel, Supplementary Fig. 3a), but the numbers of CD $4^{+}$and $\mathrm{CD}^{+} \mathrm{T}$ cells were roughly maintained except for an increase in $\mathrm{CD} 4^{+} \mathrm{T}$ cell numbers in the spleen (Fig. 1c, right pane/). The percentage of $\mathrm{CD} 62 \mathrm{~L}^{\text {hi}} \mathrm{CD} 44^{\text {lo }}$ naïve cells was dramatically decreased in both $\mathrm{CD} 4^{+}$and $\mathrm{CD} 8^{+}$ $\mathrm{T}$ cell populations, indicating that majority of the $\mathrm{T}$ cells were activated or became memory cells (Fig. 1d,e and Supplementary Fig. 3b). We also observed a reduction in the percentage of $B$ cells and an increase in the percentage of $\mathrm{CD} 11 \mathrm{~b}^{+} \mathrm{Gr} 1^{+}$myeloid cells (Supplementary Fig. 4).

\section{Dysregulated cell surface phenotype of Tet2/3-deficient Treg cells}

We next examined the phenotypic features of Tet2/3-deficient Treg cells. The frequency of Foxp3 ${ }^{+}$Treg cells (as a percentage of total $\mathrm{CD}^{+} \mathrm{T}$ cells) was increased in spleen as well as in peripheral and mesenteric lymph nodes of Tet2/3 ${ }^{f / f l}$ Foxp3 ${ }^{\text {Cre }}$ mice relative to that of WT mice (Fig. 2a,b). Despite the increase in frequency, Tet2/3 DKO Treg cells had lower expression levels of CD25 (the IL-2 receptor $\alpha$ chain), a signature surface cytokine receptor of Treg and activated T cells; they also displayed a significant decrease in the 
expression of neuropilin-1 (Nrp1), an important mediator of Treg homeostasis and function ${ }^{28}$, in both spleen and lymph nodes (Fig. 2c). Flow cytometric analysis revealed varying degrees of increased expression and/or an increased proportion of cells expressing the transcription factor Helios (lkzf2) and the surface proteins ICOS, CD103, GITR, CTLA-4 and PD-1 in Tet2/3 DKO compared to those in WT Treg cells, especially in the spleen; but similar expression of CD127, the IL-7 receptor $\alpha$ chain (Fig. 2d). Both Nrp1 and Helios have been reported to be markers of thymic-derived Treg cells and were used to distinguish thymic-derived Treg cells from peripherally-induced Treg cells ${ }^{29,30,31}$; however, the reliability of these markers is still controversial ${ }^{32,33}$. The expression of Nrp1 was downregulated in Treg cells from mesenteric lymph nodes in Tet2/3 ${ }^{f / f l}$ Foxp $3^{\text {Cre }}$ mice compared to that of WT mice, while the expression of Helios was increased (Supplementary Fig. 3c). The chemokine receptor CCR7, which is important for the migration and function of Treg cells ${ }^{34}$, was also significantly downregulated in Treg cells from Tet2/3//fll Foxp3 ${ }^{\text {Cre }}$ compared to WT mice (Supplementary Fig. 3d). Moreover, compared to their WT counterparts, Treg cells from Tet2/3 ${ }^{f / f t}$ Foxp $3^{\text {Cre }}$ mice showed a decreased proportion of CD62L hi CD44 ${ }^{\text {lo }}$ naïve cells (Fig. 2e) and a higher frequency of CD69+ recently activated cells (Fig. 2f), indicating that Tet2 and Tet3 deficiency in Treg cells results in an activated phenotype and dysregulated expression of multiple Treg activation and phenotypic molecules. The increased frequency and activation status of Treg cells that we observe in Tet2 $/ 3^{f / f t} F o x p 3^{C r e}$ mice is also commonly observed in mice with Treg perturbations, and may reflect a compensatory increase in Treg cell numbers observed under conditions of insufficient overall Treg cell function ${ }^{8,35}$.

\section{Decreased long-term suppressive function of Tet2/3-deficient Treg cells}

To investigate the in vivo function of Treg cells isolated from Tet2/3 ${ }^{f / / f l} F o x p 3^{C r e}$ DKO mice, we used a mouse model in which we attempted to correct the scurfy phenotype. Scurfy mice lack Treg cells because they carry a natural frame-shift mutation of in the Foxp3 gene that abrogates Foxp3 protein expression ${ }^{36}$. Transfer of peripheral $\mathrm{CD}^{+} \mathrm{T}$ cells from scurfy male mice into Rag1-deficient recipients leads to an expansion of autoreactive scurfy $\mathrm{CD}^{+} \mathrm{T}$ cells and severe autoimmune inflammation due to a lack of effective Treg cell suppression; both features can be suppressed by co-transfer of congenically-marked WT Treg cells ${ }^{37}$. We transferred $5 \times 10^{5}$ scurfy CD4 ${ }^{+} \mathrm{T}$ cells $\left(\mathrm{CD} 45.1^{+}\right)$into Rag1-deficient recipient mice together with $1 \times 10^{5}$ Treg cells from CD $45.2^{+}$mice, either WT Foxp $3^{\text {Cre }}$ or Tet2/3 ${ }^{f / f l} F o x p 3^{C r e} D K O$ mice (Supplementary Fig. 5a). In this short-term in vivo suppression assay, Treg cells isolated from Tet2/3/flfl Foxp $3^{\text {Cre }}$ mice suppressed the expansion of scurfy $\mathrm{CD} 4^{+} \mathrm{T}$ cells to almost the same extent as Treg cells isolated from WT Foxp $3^{\text {Cre }}$ mice, as evidenced by decreased expansion of CD45.1+ scurfy cells measured in spleen and lymph nodes 4-5 weeks after adoptive transfer (percentages, Supplementary Fig. 5b; total cell numbers, Supplementary Fig. 5c). As we previously observed for Treg cells from Tet2/3 ${ }^{f / / f l} C D 4^{\text {Cre }}$ mice ${ }^{12}$, Treg cells isolated from Tet2/3 fl/fl Foxp $3^{\text {Cre }}$ mice were more likely to lose Foxp3 expression compared to WT control Treg cells (Supplementary Fig. 5b,c).

To examine Treg function over a longer time course, we transferred bone marrow cells from scurfy mice into sublethally irradiated Rag $^{1 /-}$ recipient mice, alone or together with bone marrow cells from WT or Tet2/3 ${ }^{f / f f}$ Foxp3 ${ }^{\text {Cre }}$ DKO mice (Supplementary Fig. 5d,e). As expected ${ }^{38}$, recipient mice receiving scurfy bone marrow cells alone started to lose weight at 4 weeks and succumbed 6-7 weeks after transfer. Co-transfer of WT bone marrow cells suppressed scurfy cell expansion and protected the recipient mice from death, whereas co-transfer of Tet2/3 DKO bone marrow cells failed to protect the recipient mice, which lost weight after 9 weeks and died at 11-13 weeks after transfer (Supplementary Fig. 5d,e). Together, these data indicate that Tet2/3-deficient Treg cells from Tet2/3 $3^{\mathrm{fl} / \mathrm{fl}}$ Foxp3 ${ }^{\mathrm{Cre}}$ mice have normal in vivo suppressive function in the shortterm that is not sustained in the long-term.

\section{Moderate DNA hypermethylation at Foxp3 CNS2 in Tet2/3 DKO Treg cells}


The expression of Foxp3 during Treg cell differentiation is regulated by three conserved noncoding sequence (CNS) elements located in the first intron of the Foxp3 gene ${ }^{39}$. Among these, CNS1 and CNS2 have been shown to control the stability of Foxp3 expression in a manner linked to the DNA modification status of these elements ${ }^{12,13}$. Given that TET proteins catalyze the process of loss of $5 \mathrm{mC}$ at CNS1 and CNS2 during Treg development in vivo ${ }^{12}$, we examined the DNA modification status at Foxp3 CNS1 and CNS2 in $\mathrm{CD}^{+} \mathrm{CD}^{2} 5^{+} \mathrm{YFP}^{+}$peripheral Treg cells isolated from male WT or Tet2/3 ${ }^{\text {fl/fl}}$ Foxp3 ${ }^{\text {Cre }}$ mice using bisulfitesequencing (BS-seq). The results clearly show impaired DNA demethylation (assessed as loss of $5 \mathrm{mC}$ ) in Foxp3 CNS1 and CNS2 in Treg cells isolated from Tet2/3 ${ }^{f / f l} F o x p 3^{C r e}$ mice; however, this impairment was less pronounce (i.e. $5 \mathrm{mC}+5 \mathrm{hmC}$ levels assessed by BS-seq were lower) than we had previously observed in Treg cells isolated from Tet2/3/flll $C D 4^{\text {Cre }}$ mice (Fig. 3a,b). This result is likely to reflect the chronological order of CD4 ${ }^{\text {Cre }}$ versus Foxp3 ${ }^{\text {Cre }}$ expression: CD4 $^{\text {Cre }}$ mediates Tet2 and Tet3 deletion at an earlier developmental stage compared to Foxp3 ${ }^{\text {Cre }}$. Consistent with this difference, CpG sites \#6 and \#9-11 in the CNS2 region, which have already initiated the process of loss of $5 \mathrm{mC}$ at the Foxp $3^{+} \mathrm{CD} 25^{-}$precursor stage ${ }^{12}$, were efficiently demethylated in Tet2/ $/ 3^{f / f l}$ Foxp3 ${ }^{\text {Cre }}$ Treg cells. We also examined several other regulatory regions that show Treg-specific hypomethylation: II2ra intron 1a, Tnfrsf18 exon 5, Ikzf4 intron 1b and Ctla4 exon $2^{40}$. The DNA modification status at II2ra intron 1a, Tnfrsf18 exon 5 and Ikzf4 intron 1b showed similar pattern compare to that of Foxp3 CNS1 and CNS2 regions: DNA demethylation was impaired in Treg cells isolated from

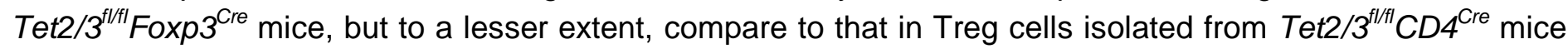
(Fig. 3c-3e). However, at Ctla4 exon 2, the levels of impairment in DNA demethylation were similar regardless of whether Treg cells were isolated from Tet2/3 ${ }^{f / f f l} F o x p 3^{C r e}$ mice or Tet2/3 ${ }^{f / f f l} C D 4^{C r e}$ mice (Fig. 3f).

\section{Dysregulated expression of genes involved in cell cycle, DNA damage repair and immune processes in Tet2/3 DKO Treg cells}

To further investigate the molecular mechanisms by which TET proteins control Treg cell identity and function, we compared the transcriptional profiles of $\mathrm{CD}^{+} \mathrm{YFP}^{+}$Treg cells sorted from 14-weeks old Foxp3 ${ }^{\text {Cre }}$ WT and Tet2/3 ${ }^{f / f l}$ Foxp3 ${ }^{C r e}$ DKO mice (2 biological replicates each, isolated from pooled spleen and peripheral lymph nodes). We isolated RNA from two Tet2/3 ${ }^{\text {fl/fl }} F o x p 3^{C r e}$ DKO littermates with the assumption that these mice would have comparable phenotypes. However, when sacrificed, one of these mice (labeled with an asterisk: $\mathrm{DKO}^{*}$ ) clearly showed more severe splenomegaly than its littermate (DKO). This difference was obvious in principal component analysis (PCA) of the RNA-seq data: the biological replicates of WT cells, whether Treg or CD4 ${ }^{+}$Foxp3 ${ }^{-}$cells, clustered closely together, while those from Treg and CD4 ${ }^{+}$Foxp3 $^{-}$cells $^{-}$ obtained from the two 14-weeks old Tet2/3 ${ }^{f / f l} F o x p 3^{C r e}$ DKO littermates were not as closely aligned (Supplementary Fig. 6a). As expected, both Treg and CD4 ${ }^{+} \mathrm{T}$ cells from the Tet2/3 ${ }^{\text {fl/fl}}$ Foxp3 ${ }^{\text {Cre }}$ DKO mouse with less severe splenomegaly more closely resembled the corresponding WT cells, whereas cells from the mouse with more severe splenomegaly (marked with an asterisk) were less similar to WT (Supplementary Fig. 6a). Nevertheless, scatter plots of the data showed reasonably good correlation between the two replicates from Tet2/3 DKO Treg and CD4 ${ }^{+} \mathrm{T}$ cells (0.92 and 0.90 respectively), although the correlation between the WT replicates was stronger (0.94 and 0.93 respectively) (Supplementary Fig. 6b,c). Based on these data, we averaged the two DKO replicates for subsequent analyses.

Based on a cut-off of FDR (false discovery rate) $\leq 0.05$ and a fold change $\geq 1.5,1565$ genes were differentially expressed, with 1156 genes being upregulated and 409 genes being downregulated in Tet2/3 DKO Treg cells compared to WT Treg cells (Fig. 4a). Seventy-six Treg signature genes were differentially expressed (Table S2) and a selected subset (Foxp3, Nrp1, I/1rl1, Prg4, Dnahc7b and Klrg1) are pointed out in the mean average (MA) plot (Fig. 4a). Ingenuity pathway analysis (IPA) of the differentially expressed genes showed that Tet2/3 deficiency in Treg cells affected three main categories of canonical pathways (Fig. 4b and Table S3): genes involved in DNA damage, DNA repair (Brca1, Atm, Rad50) and cell cycle (Cdkn1a, Cdkn2a, 
Hipk2) (green bars); genes implicated in immune cell function such as the antigen presentation pathway ( $\mathrm{H} 2-$ $A a, H 2-A b$ and $H 2-E b 1)$, Th1 and Th2 activation pathways, etc (blue bars); and genes related to molecular mechanisms of cancer (orange bars).

A recent study demonstrated that microbial-mediated inflammatory signals were critical for myeloid expansion of Tet2-deficient mice ${ }^{41}$. Therefore, we used RNA-seq to examine the transcriptional profiles of $\mathrm{CD}^{+} \mathrm{YFP}^{+}$Treg cells sorted from mesenteric lymph nodes of 14 -week old WT and Tet2/3//fl Foxp3 ${ }^{\text {Cre }}$ DKO mice (3 biological replicates each). There was good correlation among the biological replicates (Table S4). Based on a cut-off of FDR (false discovery rate) $\leq 0.05$ and a fold change $\geq 1.5,2073$ genes were differentially expressed, with 1449 genes being upregulated and 624 genes being downregulated in Tet2/3 DKO Treg cells compared to WT Treg cells (Supplementary Fig. 7a). A handful of them overlapped with the differentially expressed genes from Tet2/3 DKO vs WT Treg cells isolated from pooled spleen and pLN (Supplementary Fig. 7b). IPA analysis of the differentially expressed genes indicated that similar canonical pathways were affected, including genes involved in cell cycle, DNA damage, immune cell function and cancer development (Supplementary Fig. 7c and Table S5).

The majority of cell cycle-related genes were upregulated in Tet2/3 DKO Treg cells (see heatmap of Fig. 4c and Supplementary Fig. 7d), prompting us to assess the proliferation of Tet2/3 DKO Treg cells in vivo. We injected WT and Tet2/ $3^{f / f l}$ Foxp $3^{C r e}$ DKO mice with BrdU, a thymidine analog that is incorporated into newly synthesized DNA during replication, and analyzed Treg cells $24 \mathrm{~h}$ later. Indeed, Tet2/3 DKO Treg cells incorporated significantly more BrdU compared to WT Treg cells (Fig. 4d). The genes involved in DNA damage pathways also prompted us to examine the level of phosphorylated histone H2A.X ( $\mathrm{HH} 2 \mathrm{AX}$ ), an early marker of DNA damage ${ }^{42}$, by flow cytometry. In fact, the MFI (mean fluorescent intensity) of $y$ H2AX staining was significantly increased in both Treg cells and $\mathrm{CD}^{+}{ }^{+} \mathrm{Foxp} 3^{-}$cells in spleen and $\mathrm{mLN}$ isolated from Tet2/3 ${ }^{f / f t}$ Foxp ${ }^{\text {Cre }}$ compared to WT mice (Supplementary Fig. 8). But we did not observe any increase in the level of active caspase-3, an early stage apoptosis marker, in Treg cells from Tet2/3 ${ }^{\text {fl/fl}}$ Foxp3 ${ }^{\text {Cre }}$ DKO mice compared to WT mice (Supplementary Fig. 9). Analysis of the TCR repertoire using RNA-seq reads mapping to the CDR3 region at Tcrb showed greater clonal expansion in both Treg cells and CD4 ${ }^{+}$Foxp3 ${ }^{-}$cells isolated from Tet2/3//fll Foxp3 ${ }^{\text {Cre }}$ compared to WT mice (Supplementary Fig. 10 and Table S6 and S7), suggesting antigen-driven expansion.

Compared to WT mice, expression of genes involved in Tfh differentiation, including Gzmb, Pdcd1, Bcl6, Maf, Cxcr5 and II21, was unaltered or only mildly increased in Treg cells isolated from the Tet2/3 ${ }^{f / f l}$ Foxp3 ${ }^{\text {Cre }}$ mouse with moderate splenomegaly (DKO), but markedly increased in Treg cells isolated from the littermate mouse with more severe splenomegaly (DKO*) (Fig. 4e, left pane/). Genes related to Tfh and Th17 cell differentiation (II17a, II17f, Rorc) in CD4 ${ }^{+}$Foxp3 ${ }^{-} \mathrm{T}$ cells displayed a similar trend (Fig. 4e, right

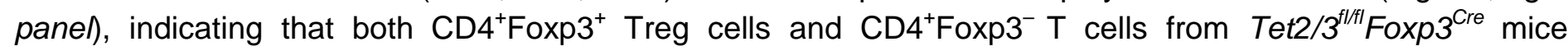
displayed skewing to Tfh and/or Th17 lineages in a manner that correlated directly with disease severity. The skewed Tfh and/or Th17 lineages were also observed in Treg cells and CD4 ${ }^{+}$Foxp3 ${ }^{-}$T cells isolated from mLN of Tet2/3 $3^{\text {fl/fl }}$ Foxp3 ${ }^{\text {Cre }}$ mice (Supplementary Fig. 7e).

In WT mice at steady state, fewer than $5 \%$ of $C D 4^{+} T C R \beta^{+}$T cells from spleen and mesenteric lymph nodes stained positive for the Tfh signature molecules CXCR5 and PD-1, but this percentage was much higher in the spleen and mesenteric lymph nodes of Tet2/3/f/fl Foxp3 ${ }^{\text {Cre }}$ mice (Fig. 4f). In addition, spleen and mesenteric lymph nodes of Tet2/3//fll Foxp3 ${ }^{\text {Cre }}$ mice had more germinal center (GC) B cells, as judged by expression of the GC signature markers GL7 and CD95 (Fig. 4g).

\section{Unexpected disease development in $T e t 2 / 3^{f / f l} F o x p 3^{W T / C r e}$ heterozygous females and mixed bone chimeras}


Foxp3 is encoded on the X-chromosome, hence due to random X-inactivation, Tet2/3f/ffl female mice that are heterozygous for Foxp $3^{\text {Cre }}\left(\right.$ Foxp $\left.3^{\text {WT/Cre }}\right)$ should harbor both Tet2/3-deleted Treg cells (Foxp $3^{\text {Cre }}$ positive) and WT Treg cells (Foxp ${ }^{\text {Cre }}$-negative). Thus, the presence of WT Treg cells should in theory prevent the mice from developing any autoimmune disease. Surprisingly, we found that female mice heterozygous for Foxp $3^{\text {Cre }}$ also developed lymphoproliferative disease beginning as early as 15 weeks of age, and all mice succumbed by the age of 38 weeks (Fig. 5a). As expected, the total cellularity of the spleen from Tet2/3//fll Foxp3 ${ }^{W T / C r e}$ female mice was significantly increased compared to WT female mice (Fig. 5b).

To confirm this observation independently, we generated mixed bone marrow chimeras by adoptively co-transferring WT $\left(C D 45.1^{+}\right)$bone marrow cells together with bone marrow cells (CD45.2 $)$isolated from WT

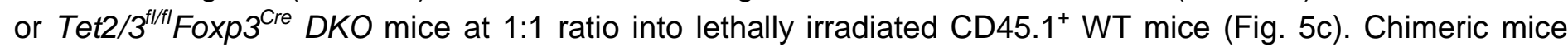
given either WT or Tet2/3 ${ }^{f / f t}$ Foxp $3^{\text {Cre }}$ DKO bone marrow cells were similar and appeared relatively normal at 14-16 weeks after bone marrow transfer (Supplementary Fig. 11). However at 18-20 weeks after adoptive transfer, the DKO bone marrow chimeras developed splenomegaly compared to the WT chimeras and showed a significant increase of total cellularity in the spleen (Fig. $5 \mathrm{~d}$ ).

Notably, CD $45.2^{+}$cells in mixed chimeras with Tet2/3 $3^{f / f l}$ Foxp $3^{\text {Cre }}$ DKO bone marrow showed considerably higher capacity for expansion compared to CD45.2 $2^{+}$cells in WT mixed bone marrow chimeras (Fig. 5e,f, leftmost panels). In the DKO chimeric mice, the percentage of CD4 ${ }^{+} \mathrm{CD} 45.2^{+} \mathrm{T}$ cells was significantly higher than expected, with over $80 \%$ of $C D 4^{+} \mathrm{CD} 45.2^{+} \mathrm{T}$ cells observed in one DKO chimeric mouse; however, the percentage of $\mathrm{CD}^{+} \mathrm{T}$ cells was strongly decreased (Fig. 5e, second panels; Fig. 5f, second and third panels). The frequency of Foxp3 ${ }^{+}$cells in the CD45.2 $2^{+} \mathrm{CD}^{+}$population varied widely in the DKO mixed chimeras, with some chimeras displaying a frequency as high as $60-70 \%$, while others showed fewer than $10 \%$ of CD45.2 $2^{+} \mathrm{CD}^{+}$Foxp3 $^{+}$cells (Fig. 5e, middle panel; Fig. 5f, last panel), suggesting that Treg cells in the DKO chimeras could manifest unstable Foxp3 expression. Moreover, both $\mathrm{CD}^{+} \mathrm{Foxp}^{+}$and $\mathrm{CD}^{+}{ }^{+}$Foxp $3^{-}$DKO cells in the chimeric mice showed an activated/memory phenotype, with a strong decrease in the proportion of "naïve" CD62L hi CD44 ${ }^{\text {lo }}$ cells (Fig. 5e, last two panels). Together these data indicate that the loss of $T$ regulatory function in Tet2/3 DKO Treg cells is dominant, and cannot be rescued or prevented in the presence of WT Treg cells.

\section{Fate-mapping reveals unstable Foxp3 expression in Tet2/3 DKO Treg cells}

Although Foxp3 ${ }^{+}$Treg cells are generally stable and are marked by sustained expression of Foxp3, they may lose Foxp3 expression under certain conditions and develop into cells resembling effector $T$ cells, designated "ex-Treg" cells ${ }^{5}$. To examine whether Tet2/3-deficient Treg cells indeed lose Foxp3 expression and become ex-Treg effector cells, we introduced the Rosa26-YFP ${ }^{L S L}$ allele ${ }^{43}$ into Tet2/3//fll Foxp $3^{\text {Cre }}$ mice. In the LSL (LoxP-STOP-LoxP) cassette, a strong transcriptional stop site is flanked by two LoxP sites and inserted into the Rosa26 locus ahead of the cDNA sequence encoding YFP, ensuring that YFP expression is turned on only in Cre-expressing cells. Since YFP expression from the Rosa26 locus is much brighter than YFP expression from the YFP-Cre fusion protein introduced into the 3' UTR of the Foxp3 gene, cells expressing YFP from the Rosa26 locus can be easily distinguished from cells expressing the YFP-Cre fusion protein encoded in the Foxp3 gene ${ }^{44}$ (Fig. 6a, where intermediate YFP expression derives from the YFP-Cre fusion protein whereas high YFP expression derives from the Rosa26 fate mapping allele). Analysis of CD4 ${ }^{+} \mathrm{T}$ cells from spleen and mesenteric lymph nodes of Tet2/3 ${ }^{f / f l} F o x p 3^{C r e}$ Rosa26-YFP ${ }^{L S L}$ mice showed clearly that a much higher proportion of Rosa-YFP ${ }^{\text {high }}$ cells - cells that had turned on Cre from the Foxp3 gene, and thus had been Treg cells earlier in their developmental history - had lost Foxp3 expression and turned into ex-Treg cells, compared to Rosa-YFP ${ }^{\text {high }}$ cells from heterozygous Tet2 $^{+/ f l}$ Tet $^{f / f f}$ Foxp $^{\text {Cre }}$ Rosa26-YFP mice (Fig. 6a, b). Further confirming the existence of ex-Treg cells in Tet2/3 $3^{f / f l} F o x p 3^{C r e}$ mice, we showed by quantitative real-time PCR as well as RNA-seq that Tet2 and Tet3 mRNAs were both greatly reduced in expression in CD4 ${ }^{+} \mathrm{YFP}^{-}$ 
cells isolated from Tet2/3/f/fl Foxp3 ${ }^{\text {Cre }}$ compared to WT mice (qPCR, Supplementary Fig. 12a; number of normalized reads mapping to the deleted exons; Supplementary Fig. 12b-c). Taken together with the data presented in the previous sections, this finding suggests strongly that a substantial fraction of the activated $\mathrm{CD}^{+}{ }^{+} \mathrm{FP}^{-} \mathrm{T}$ cells in Tet2/3/flfl Foxp3 ${ }^{\mathrm{Cre}}$ mice (Fig. 5e,f) are ex-Treg cells that have lost suppressive function and acquired deleterious effector function.

\section{Transfer of total CD4 ${ }^{+} \mathrm{T}$ cells from Tet2/3 DKO mice elicits disease in immunocompetent mice}

To test the above hypothesis of deleterious effector function acquired by ex-Treg cells from

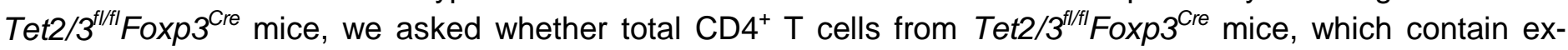
Treg cells as well as bystander activated $\mathrm{CD}^{+} \mathrm{T}$ cells, could elicit disease when transferred into healthy immunocompetent recipient mice. We transferred purified CD4 ${ }^{+} \mathrm{T}$ cells $\left(5 \times 10^{6}\right.$; purity $\left.>98.5 \%\right)$ from spleen and peripheral lymph nodes into fully immunocompetent (non-irradiated) congenic CD45.1+ recipient mice (Fig. 7a). All the recipients developed enlarged spleen and lymph nodes and developed disease 7-10 weeks after transfer (Fig. 7b). Tet2/3 DKO CD4 ${ }^{+} \mathrm{T}$ cells expanded 3-50 fold, from the starting transferred population of 5 million cells to as many as 250 million cells (Fig. 7b). The percentage of Foxp $3^{+}$cells after expansion of the transferred $\mathrm{CD}^{+}$population varied from mouse to mouse, with three mice showing high-level Foxp3 expression (mouse example 1 in Fig. 7c), and the others showing low to no expression of Foxp3 (mouse example 2 in Fig. 7c). We observed a compensatory expression of Foxp3 ${ }^{+}$cells in CD45.1 ${ }^{+}$host cells in each individual (Fig. 7b and 7c). Moreover, both CD4 ${ }^{+}$Foxp3 ${ }^{+}$host Treg cells and CD4 ${ }^{+}$Foxp3 ${ }^{-}$host cells displayed activated phenotype with low levels of CD62L expression and high levels of CD44 expression (Fig. 7c, Host Cells). Together these data suggest that Tet2/3 DKO CD4 ${ }^{+} \mathrm{T}$ cells contained the cell population responsible for transferring the diseases to immunocompetent mice. These might be ex-Treg effector cells, host CD4 ${ }^{+} \mathrm{T}$ cells that became activated and converted to effector cells, or both.

\section{Discussion}

Although ectopic expression of Foxp3 in conventional $\mathrm{CD} 4^{+} \mathrm{T}$ cells confers suppressive activity as well as expression of many Treg signature genes 45, 46, 47, Foxp3 expression by itself does not recapitulate all aspects of the bona fide Treg transcriptional and epigenetic landscape, nor does it result in stable, long-lasting immune suppressive function 19, 48, 49. Here, we investigated the role of two epigenetic regulators, the methylcytosine oxidases Tet2 and Tet3, in Treg function. We show that mice with Treg-specific deletion of Tet2 and Tet3 (Tet2/3 ${ }^{\text {fl/fl}}$ Foxp3 ${ }^{\text {Cre }}$ DKO mice) display defective Treg function and develop an inflammatory disease characterised by splenomegaly and lymphocyte infiltration into tissues. The inflammatory phenotype had three interrelated causes. First, TET loss-of-function in developing Tet2/3 ${ }^{\text {fl/fl}} F o x p 3^{C r e} D K O$ Treg cells led to increased methylation $(5 \mathrm{mC}+5 \mathrm{hmC})$ at the Foxp3 CNS1 and CNS2 enhancers compared to wildtype Treg cells. Second, increased methylation at these intronic enhancers resulted in decreased stability of Foxp3 expression and impaired Treg cell function. Third, both ex-Treg cells and conventional CD4 ${ }^{+}$and $\mathrm{CD}^{+} \mathrm{T}$ cells in Tet2/3 ${ }^{f / f f}$ Foxp3 ${ }^{\text {Cre }}$ DKO mice developed an aberrant dominant effector phenotype, which could not be suppressed by the presence of wildtype Treg cells in Tet2/3 $3^{f / f t} F o x p 3^{W T / C r e}$ heterozygous females or in mixed bone marrow chimeras. Our data emphasize the essential role of TET-mediated epigenetic modifications not only in maintaining the demethylated status of the Foxp3 CNS1 and CNS2 enhancers, thereby stabilizing Foxp3 expression, specifying Treg cell lineage and conferring stable Treg identity, but also in preventing indirectly the acquisition of aberrant effector function by bystander CD4 ${ }^{+}$and $\mathrm{CD} 8^{+} \mathrm{T}$ cells with otherwise normal TET function.

In our animal facility, mice lacking only Tet2 or Tet3 in Treg cells showed mild phenotypes if any ${ }^{12}$, indicating that Tet2 and Tet3 have redundant functions in Treg cells as we previously observed for myeloid cells, B cells and iNKT cells ${ }^{22,23,25}$. Consistent with this hypothesis of redundant function, Treg cells deficient 
in both Tet1 and Tet2 also showed increased CNS2 methylation, impaired Treg cell differentiation and impaired suppressor function in vivo and in mixed bone marrow chimeras ${ }^{26}$. In contrast, a previous report suggested that Treg cells from mice lacking Tet2 alone had a surprisingly high increase in the level of $5 \mathrm{mC}+5 \mathrm{hmC}$ at CNS2 ${ }^{50}$. Similarly variable phenotypes have been reported for myeloid expansion in Tet2deficient mice, with some Tet2 ${ }^{-/}$mouse strains showing no striking phenotypes compared to control littermate mice and others developing premalignant diseases or frank leukemias ${ }^{51,52,53,54,55,56}$. This unusually large variation in the myeloid and Treg cell phenotypes of Tet2-deficient mice may be related to the animal facility in which the mice are housed: myeloid expansion in Tet2-deficient mice has been attributed, at least in part, to the influence of cytokines such as IL-6 produced in response to gut microbiota, since it is eliminated or greatly attenuated if the mice are housed in a germ-free facility ${ }^{41}$. Even in $12-16$ week-old Tet2/3 $3^{f / f l}$ Foxp $3^{\text {Cre }}$ mice, the large increase in the cellularity of mesenteric lymph nodes compared to peripheral lymph nodes (Fig. 1b, Supplementary Fig. 1c) and the increased clonality of both Foxp3 ${ }^{+}$Tregs and CD4 ${ }^{+}$Foxp3 ${ }^{-}$T cells (ex-Treg cells and/or activated CD4 ${ }^{+}$bystander $\mathrm{T}$ cells) (Supplementary Fig. 10) suggests a role for recognition of microbial or other antigens. We conclude that depending on the cell type, the effects of TET loss-of-function are most strikingly manifested when TET-deficient cells are subjected to stimulation, for instance through antigen recognition ${ }^{25}$, cytokine stimulation ${ }^{11}$, or the influence of the microbiota as discussed above ${ }^{41}$.

Tet2 $/ 3^{f / f l} F o x p 3^{C r e}$ mice showed later disease onset and lower levels of $C N S 1 / C N S 2$ methylation compared to Tet2/3/flf $C D 4^{\text {Cre }}$ mice ${ }^{12}$. This likely reflects the two distinguishing features of these two mouse strains. First, $C D 4^{C r e}$ expression precedes Foxp $3^{\text {Cre }}$ expression during Treg development. Because $5 \mathrm{hmC}$ and $5 \mathrm{fC}$ are relatively stable epigenetic marks that are primarily lost by passive dilution during cell division ${ }^{57,58,59}$,

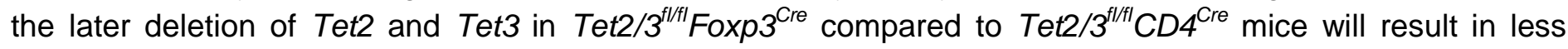
extensive loss of TET proteins and oxidized methylcytosines, thus in turn leading to a less extensive increase of methylation at CNS1 and CNS2. This translates into a slower loss of Treg function and concomitant slower increase of cytokine expression, and therefore a slower kinetics of disease development in Tet2/3/ffl Foxp $3^{\text {Cre }}$ mice compared to Tet2 $/ 3^{f / f l} C D 4^{\text {Cre }}$ mice. Second, Tet2 $/ 3^{f / f l} C D 4^{\text {Cre }}$ mice show a dramatic expansion of iNKT cells that is not observed in Tet2/ $3^{f / f l} F o x p 3^{C r e}$ mice ${ }^{25}$. This is known to lead to an aberrant increase in the production of IFN $\gamma$, IL-17 and other cytokines ${ }^{11,25}$, presumably further compromising immune homeostasis and $\mathrm{T}$ regulatory function and leading to more rapid disease onset in Tet2/3//fl$C D 4^{\mathrm{Cre}}$ mice. A similar process of gradually increased cytokine production is observed in adult Tet2/3//fll Foxp $3^{\text {Cre }}$ mice (Fig. $4 \mathrm{e}$ ), but in this case the cytokines are produced by ex-Treg cells as well as activated T cells (see below).

Our fate-mapping experiments showed unambiguously that Foxp3 expression in Treg cells from Tet2/3 ${ }^{f / / f l}$ Foxp3 ${ }^{\text {Cre }}$ DKO mice was considerably less stable than Foxp3 expression in Treg cells from control mice (Fig. 6). Not only were Treg cells from Tet2/3 ${ }^{f / f l} F o x p 3^{C r e} D K O$ mice more prone to lose Foxp3 expression, they also showed dysregulated expression of many Treg signature genes including Cd25, Nrp1 and IIrl1. Two points are particularly noteworthy. First, in Tet2/3 ${ }^{f / f l} F o x p 3^{W T / C r e}$ heterozygous females or mixed bone marrow chimeras, the presence of wildtype Treg cells was not sufficient to suppress the aberrant inflammation

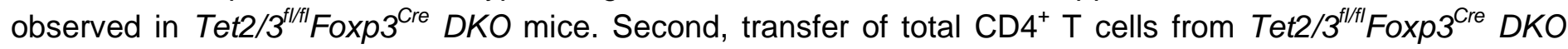
mice into immunocompetent recipient mice unexpectedly resulted in efficient transfer of the inflammatory disease. In both the mixed bone marrow chimeras and the CD4 ${ }^{+} \mathrm{T}$ cell transfer experiments, we noticed a large variation in Foxp3 expression at the time of analysis, with some mice showing 60-70\% of Foxp3expressing cells but others showing fewer than $10 \%$ of Foxp3-expressing cells. The data indicate that Foxp ${ }^{+}$ cells from Tet2/3/f/fl Foxp $3^{\mathrm{Cre}}$ DKO mice expand somewhat more extensively than control cells in an early phase (see below) in which they maintain almost normal suppressive function; later, however, they lose Foxp3 expression and suppressive function (Fig. 5) but acquire effector function (Fig. 4), leading to the accumulation of effector ex-Treg cells as well as activated bystander $\mathrm{CD}^{+}$and $\mathrm{CD}^{+} \mathrm{T}$ cells as the mice age. Overall, therefore, loss of TET function in Treg cells of Tet2/3/f/fl$F o x p 3^{C r e} D K O$ mice results in a paradoxical dominant 
disease, in which the defective TET-deficient Treg cells lose Foxp3 expression and suppressor function on the one hand, and convert to ex-Treg cells with dominant effector function on the other hand. Notably, these defective Treg cells and effector-like ex-Treg cells are able to confer an activated phenotype even to bystander $\mathrm{CD}^{+} \mathrm{T}$ cells (Fig. 7).

A notable feature of Treg cells from Tet2/3 $3^{f / f l} F o x p 3^{C r e} D K O$ mice was aberrantly high proliferation and expansion compared to wildtype Treg cells (Fig. 2b, 4d). This phenomenon appears to be a consistent feature of TET-deficient cells: Tet2/3 DKO Treg cells showed a significantly higher proliferation rate compared to WT Treg cells (Fig. 4d); both Treg cells and CD4 ${ }^{+}$Foxp3 ${ }^{-}$cells from Tet2/3//fll Foxp3 ${ }^{\text {Cre }}$ mice showed greater clonal expansion compared to WT mice (Supplementary Fig. 10); and both iNKT cells from Tet2/3 fl/fl $C D 4^{\text {Cre }}$ mice ${ }^{25}$

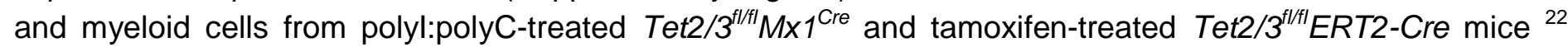
displayed a pronounced tendency to expansion and proliferation compared to their WT counterparts. Even Treg cells from younger (14 week) Tet2/3 $3^{f / f l} F o x p 3^{C r e} D K O$ mice, isolated from apparently healthy mice before the development of severe inflammatory disease, showed altered expression of genes involved in cell cycle, DNA damage repair, immune processes and cancer compared to WT Treg cells (Fig. 4a-c). While the increased expansion of cells with TET loss-of-function appears to be facilitated by stimulation as discussed above, the underlying mechanisms remain to be elucidated.

In addition to simply losing suppressive function, ex-Treg cells appear to be prone to acquire effector function ${ }^{49}$. Again, the underlying mechanisms are not yet completely clear, but it is known that mice with Treg perturbations frequently compensate for insufficiency of $T$ regulatory function by becoming hyperproliferative and hyperactivated ${ }^{8,35}$. For instance, ex-Treg cells arising as a result of deficiency in the mTOR-signaling regulator TSC1 produce increased levels of IL-17 and acquire Th17 effector features under inflammatory conditions ${ }^{60}$; and neuropilin1-deficient Treg cells produce high levels of IFN $\gamma$, which feeds back to suppress Treg cell function ${ }^{11}$. In our case, we have shown that Tet2/3 deficiency leads to increased expression of genes related to Tfh and/or Th17 cell differentiation, both in CD4 ${ }^{+}$Foxp3 ${ }^{-}$T cells which include both ex-Treg cells and CD4 ${ }^{+}$bystander cells, and in CD4 ${ }^{+}$Foxp $3^{+}$Treg cells, in a manner that correlated directly with disease severity.

Taken together, our data emphasize the critical role of TET proteins in the maintenance of stable Foxp3 expression and the integrity of Treg gene expression and function. The absence of TET proteins in Treg cells sets off a cascade of events that begins with increased DNA methylation of CNS1 and CNS2 and unstable Foxp3 expression, both facilitated by cell division occurring as a result of antigen and cytokine stimulation; and continues into compromised suppressor function and acquisition of effector function by ex-Treg cells as well as bystander $\mathrm{T}$ cells. The aberrant acquisition of these dysregulated phenotypes eventually results in a fatal inflammatory/ lymphoproliferative disease.

\section{ACKNOWLEDGEMENTS}

We thank members of the Rao laboratory for suggestions and discussions. We thank Cheryl Kim, Denise Hinz, Lara Boggeman and Robin Simmons at the La Jolla Institute Flow Cytometry facility for help with cell sorting experiments; Jeremy Day of the La Jolla Institute Sequencing facility for help with next-generation sequencing and Dr. Zbigniew Mikulski and Margie Chadwell of the La Jolla Institute Microscopy and Histology facility for help with histological and microscopic analysis; and the Histology Core at the University of California at San Diego Moores Cancer Center. We thank Dr. Nissi Varki from University of California at San Diego for help with histology analysis. This work was supported by National Institutes of Health (NIH) R01 grants R35 CA210043 and Al 12858901 (to A.R.). FACSAria II Cell Sorter was acquired through the Shared Instrumentation Grant (SIG) Program S10 RR027366 and Hiseq2500 was funded by S100D016262. C.W.L. was supported by Irvington Postdoctoral Fellowship from the Cancer Research Institute. D.S.C. is a graduate student in the UCSD Biology Program and is supported by a CONACYT/UCMEXUS fellowship from Mexico. 
X.L. was supported by a postdoctoral Fellowship from CIRM UCSD Interdisciplinary Stem Cell Research \& Training Grant II (TG2-01154). The authors declare no competing financial interests.

Author contributions: A.R., X.Y. and C.W.L. conceived the project. A.R. supervised project planning and execution. X.Y. and X.L. performed experiments. D.S.C performed bioinformatic analyses of RNA-seq data. C.W.L. provided input for experimental design and critically evaluated the manuscript. A.R. and X.Y. wrote the manuscript.

\section{Materials and Methods}

\section{Mice}

Foxp3 ${ }^{\text {YFP-Cre }}\left(\right.$ Foxp3 $^{\text {Cre }}$ ) mice, congenic mice (strain B6.SJL-Ptprc ${ }^{\text {aPepc }}$ /BoyJ) and scurfy mice were obtained from Jackson Laboratory. Tet2 $2^{f / f t}$ Tet $^{f / / f /}$ Foxp3 ${ }^{\text {Cre }}$ mice were generated in our laboratory by crossing

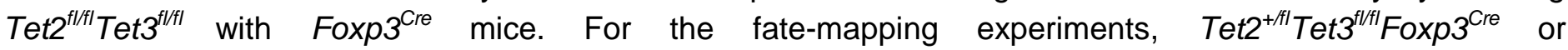

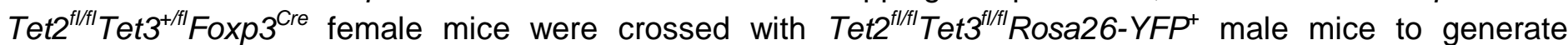
Tet2 $^{f / f t}$ Tet $^{f / / f l}$ Foxp $^{\text {Cre }}{ }^{\text {Rosa26-YFP }}{ }^{+}$male mice for further analysis. Age of the mice used for each experiment was stated in the figure legends. All breeding and experiments were reviewed and approved by the Institutional Animal Care and Use Committee of the La Jolla Institute for Allergy and Immunology.

\section{Cell Preparation and Flow cytometry}

Single-cell suspensions were prepared from spleen, peripheral lymph nodes and mesenteric lymph nodes for staining or cell sorting. All the antibodies used for flow cytometry analyses and FACS sorting were purchased from eBioscience and Biolegend except for the CD95 (Fas) antibody which was purchased from BD Biosciences. For analysis of $\mathrm{T}$ cell compartments and Treg cell features, single-cell suspensions were stained with anti-mouse antibodies CD4 (GK1.5), CD8 (53-6.7), CD62L (MEL-14), CD25 (PC61), CD44 (IM7), CD45.1 (A20), CD45.2 (104), Nrp1 (3E12), ICOS (C398.4A), CD103 (2E7), GITR (YGITR765), PD1 (29F.1A12), CD127 (A7R34), CD69 (H1.2F3), CCR7 (4B12). Anti-mouse CCR7 staining was performed at $37^{\circ} \mathrm{C}$ for $30 \mathrm{~min}$. For analysis of Tfh and germinal center $B$ cells, single-cell suspensions were stained with anti-mouse antibodies TCRß (H57-597), CD19 (6D5), CXCR5 (L138D7), PD1 (29F.1A12), GL7 (GL7) and CD95 (Fas, Jo2). For intracellular staining, cells were surface-stained and then stained with anti-Foxp3 (FJK-16S, eBioscience), anti-active caspase-3 (C92-605, BD Pharmingen), anti-Helios (22F6), anti-CTLA4 (UC104.89) and anti-H2A.X phosphorylated (Ser139, 2F3) antibodies (Biolegend) using the Foxp3 Fixation/ Permeabilization kit (eBioscience) and analysed by flow cytometry.

\section{BrdU incorporation assay}

Mice were injected with $1 \mathrm{mg}$ of BrdU $(100 \mu \mathrm{l}$ of $100 \mathrm{mg} / \mathrm{ml}$ stock solution) intraperitoneally. $24 \mathrm{~h}$ later, mice were sacrificed and the cells from spleen and peripheral lymph nodes were stained for surface markers and then for BrdU according to the manufacturer's protocol (BD Pharmingen, APC BrdU flow kit 552598).

\section{Anti-dsDNA antibody ELISA}

Anti-dsDNA autoantibodies in the serum from Foxp3 ${ }^{\text {Cre }}$ WT and Tet2/3 ${ }^{f / f t}$ Foxp3 ${ }^{\text {Cre }}$ mice (11-16 weeks old) were measured with kit from Alpha Diagnostic International according to the manufacturer's protocol (ELISA Kit 5110). 


\section{LEGENDplex Mouse Immunoglobulin Isotyping Panel}

The serum immunoglobulin levels were measured with LEGENDplex Mouse Immunoglobulin Isotyping Panel according to the manufacturer's protocol (Biolegend, 740493).

\section{Analysis of Peripheral bloods from Tet2/3 $3^{f / f l}$ Foxp ${ }^{\text {Cre }}$ DKO mice}

Peripheral bloods from WT and Tet2/3//fll Foxp3 ${ }^{\text {Cre }}$ DKO mice (12-14 weeks old) were collected into tubes pretreated with EDTA (BD Biosciences, 365974). Hematological parameters including the concentrations of white blood cells (WBCs), red blood cells (RBCs) and platelets were analyzed by Hemavet 950FS (Drew Scientific).

\section{Generation of mixed bone marrow chimeras}

Bone marrow cells were obtained from tibia and fibula from Foxp $3^{\text {Cre }}$ WT mice, Tet2/3 ${ }^{\text {flffl }}$ Foxp $3^{\text {Cre }}$ mice and CD45.1 congenic mice. Erythrocytes and mature $T$ cells were then depleted from the bone marrow cells using MACS LS columns. The purified cells $\left(2.5 \times 10^{6}\right)$ from Foxp3 ${ }^{\text {Cre }}$ WT and Tet2 $/ 3^{f / f f}$ Foxp $3^{\text {Cre }}$ mice were then mixed together with cells $\left(2.5 \times 10^{6}\right)$ isolated from tibia and fibula from CD45.1 congenic mice at 1:1 ratio and transferred intravenously (i.v.) into lethally-irradiated CD45.1 congenic mice. Reconstituted mice were then sacrificed for analysis 14 to 20 weeks after adoptive transfer of bone marrow cells.

\section{Scurfy $\mathrm{CD}^{+} \mathrm{T}$ cell adoptive transfer}

Scurfy $\mathrm{CD}^{+} \mathrm{T}$ cells were isolated from spleen and peripheral lymph nodes from male Scurfy mice and purified using Dynabeads (Life Tech, purity > 98\%). $5 \times 10^{5}$ CD $45.1^{+}$CD $4^{+}$scurfy $\mathrm{T}$ cells were injected into Rag1-deficient mice alone or mixed with $1 \times 10^{5}$ Treg cells isolated from Foxp3 ${ }^{\text {Cre }}$ WT or Tet2/3 ${ }^{f / f l}$ Foxp $3^{\text {Cre }}$ mice. 4 to 5 weeks after adoptive transfer, the percentage of CD $45.1^{+}$CD $4^{+}$cells and CD $45.2^{+}$CD $4^{+}$Foxp $3^{+}$cells were analyzed by flow cytometry. Alternatively, we used bone marrow cells from scurfy mice, Foxp ${ }^{\text {Cre }}$ WT or Tet2 $/ 3^{f / f t}$ Foxp $3^{\text {Cre }}$ mice for the adoptive transfer.

\section{Tet2/3 DKO CD4 ${ }^{+} \mathrm{T}$ cell adoptive transfer}

Total $\mathrm{CD}^{+} \mathrm{T}$ cells were isolated from spleen and peripheral lymph nodes from CD45.2 ${ }^{+}$ Tet2/3/flfl Foxp3 ${ }^{\text {Cre }}$ mice and double purified using Dynabeads (Life Tech, purity $>98.5 \%$ ). $5 \times 10^{6} \mathrm{CD}^{+} \mathrm{T}^{\mathrm{f}}$ cells were adoptively transferred into immunocompetent congenic mice and analyzed 7 to 9 weeks after adoptive transfer. As a control, total $\mathrm{CD} 4^{+} \mathrm{T}$ cells isolated from CD45.2 $2^{+}$Foxp3 ${ }^{\mathrm{Cr}} \mathrm{WT}$ mice were also transferred into immunocompetent congenic mice, which did not show any cell expansion.

\section{Bisulfite (BS) sequencing}

Bisulfite sequencing was performed as described previously ${ }^{12}$. Briefly, DNA samples were treated with sodium bisulfite (MethylCode Bisulfite Conversion Kit, Invitrogen). The PCR amplicons were generated using PyroMark PCR kit (Qiagen), and quantified using Quant-iT PicoGreen dsDNA reagent (Invitrogen). PCR amplicons were then used for library preparation using NEBNext DNA Library Modules for Illumina platform (NEB). The final libraries were quantified using KAPA library quantification kit for Illumina (KAPA Biosystems), and sequenced on Miseq (300bp, paired end, Illumina). The data are based on thousands of sequence reads per amplicon. Bisulfite sequencing results were analyzed as described previously ${ }^{12}$.

\section{RNA-seq library preparation}


Total RNA were isolated from CD4 ${ }^{+} \mathrm{YFP}^{+}\left(\mathrm{Foxp}^{+}\right)$Treg cells and $\mathrm{CD}^{+}{ }^{+} \mathrm{YFP}^{-}$(Foxp3 ${ }^{-}$) T cells (from pooled spleen and pLNs in Figure 4 or from $\mathrm{mLN}$ in Supplementary Figure 6) from Foxp $3^{\text {Cre }}$ WT mice and Tet2/3 ${ }^{f / / f l}$ Foxp3 ${ }^{\text {Cre }}$ DKO mice (14-weeks old) using RNeasy plus mini kit (Qiagen). RNA-sequencing libraries were prepared using Truseq stranded mRNA kit (Illumina) according to the manufacture's protocol and sequenced at the La Jolla Institute sequencing core using Illumina HiSeq2500 single end 50bp platform.

\section{RNA-seq and TCR-seq analysis}

RNA-seq data were mapped against the UCSC mouse genome mm9 using TopHat2 ${ }^{61}$ (v2.1.1) with the following parameters "-p 16 -N 2 --max-multihits 1 --read-gap-length 1 --transcriptome-index" and the RefSeq gene annotation was obtained from the UCSC genome Bioinformatics database. The number of reads mapping to each gene was counted using featureCounts ${ }^{62}$ (subread-1.4.3-p1) with the following parameters "g gene_name -s 2". Differentially expressed genes (DEGs) between WT and Tet2/3 DKO cell types were determined using the Bioconductor package DESeq2 ${ }^{63}$ with adjusted $P$ value $<0.05$ and a fold change threshold of $>1.5$ or $<0.67$. And genes with total counts $<1$ in the sum of all conditions were removed from the analysis. Canonical pathway analysis was performed using Ingenuity Pathway Analysis software (license for La Jolla Institute).

TCR sequences were retrieved from RNA-Seq data sets, and the frequency of TCR $\beta$ chain clonotypes (CDR3 regions) was determined using MiXCR ${ }^{64}$ (mixcr-1.7-2.1) package for RNA-seq analysis with the default parameters "align -I TCR $-\mathrm{s}$ mmu $-\mathrm{p}$ rnaseq -OallowPartialAlignments=true". Two rounds of contig assembly were performed by employing the "assemblePartial" function; extension of incomplete TCR CDR3s with uniquely determined $\mathrm{V}$ and $\mathrm{J}$ genes using germline sequences was done using the "extendAlignments" function; assembly and export of the clonotypes was performed using the "assemble" and the "exportClones" (-preset min -fraction -targets -vHits -dHits -jHits -vAlignments -dAlignments -jAlignments) functions, respectively.

\section{Quantitative real-time PCR}

Total RNA was isolated using RNeasy plus mini kit (Qiagen); cDNA was synthesized using SuperScript III reverse transcriptase (Thermo Fisher). Quantitative real-time PCR was performed using FastStart Universal SYBR Green Master mix (Roche) on a StepOnePlus real-time PCR machine (Thermo Fisher). Gene expression was normalized to Hprt. Primers used to detect the expression levels of Tet2, Tet3 and Foxp3 are as following:

Tet2 forward primer: AACCTGGCTACTGTCATTGCTCCA

Tet2 reverse primer: ATGTTCTGCTGGTCTCTGTGGGAA

Tet3 forward primer: GTCTCCCCAGTCCTACCTCCG

Tet3 reverse primer: GTCAGTGCCCCACGCTTCA

Foxp3 forward primer: GGCCCTTCTCCAGGACAGA

Foxp3 reverse primer: GCTGATCATGGCTGGGTTGT

Hprt forward primer: CTGGTGAAAAGGACCTCTCG

Hprt reverse primer: TGAAGTACTCATTATAGTCAAGGGCA

\section{Histology}

Lungs, livers and spleens were isolated from $12-14$ week-old Tet2/3 $3^{f / f l}$ Foxp3 ${ }^{\text {Cre }}$ DKO mice and littermate controls. Samples were fixed using $10 \%$ formalin overnight, preserved in $70 \%$ ethanol and embedded in paraffin. The paraffin blocks were then cut and sections were stained with haematoxylin and eosin (H\&E). 


\section{Statistics}

$P$ values from unpaired two-tailed Student's $t$ test were used for all the statistical comparisons between different groups and data were displayed as mean $\pm S D$ (Prism). $P$ values are denoted in corresponding figures as: ${ }^{*} \mathrm{P}<0.05,{ }^{* *} \mathrm{P}<0.01,{ }^{* *} \mathrm{P}<0.001,{ }^{* * *} \mathrm{P}<0.0001$.

\section{Data Availability}

The authors declare that all data supporting the findings of this study are available within the article and its Supplementary information files or from the corresponding author upon reasonable request. RNA-seq data have been deposited in the Gene Expression Omnibus database under accession number GSE113694. A reporting summary for this Article is available as a Supplementary Information file.

\section{References}

1. Josefowicz SZ, Lu LF, Rudensky AY. Regulatory T cells: mechanisms of differentiation and function. Annu Rev Immunol 2012, 30: 531-564.

2. Sakaguchi S, Yamaguchi T, Nomura T, Ono M. Regulatory T cells and immune tolerance. Cell 2008, 133(5): 775-787.

3. Li X, Zheng Y. Regulatory T cell identity: formation and maintenance. Trends in immunology 2015, 36(6): 344-353.

4. Rubtsov YP, Niec RE, Josefowicz S, Li L, Darce J, Mathis D, et al. Stability of the regulatory $\mathrm{T}$ cell lineage in vivo. Science 2010, 329(5999): 1667-1671.

5. Zhou X, Bailey-Bucktrout SL, Jeker LT, Penaranda C, Martinez-Llordella M, Ashby M, et al. Instability of the transcription factor Foxp3 leads to the generation of pathogenic memory $\mathrm{T}$ cells in vivo. Nat Immunol 2009, 10(9): 1000-1007.

6. Miyao T, Floess S, Setoguchi R, Luche H, Fehling HJ, Waldmann H, et al. Plasticity of Foxp3(+) T cells reflects promiscuous Foxp3 expression in conventional $\mathrm{T}$ cells but not reprogramming of regulatory $\mathrm{T}$ cells. Immunity 2012, 36(2): 262-275.

7. Sekiya T, Kondo T, Shichita T, Morita R, Ichinose H, Yoshimura A. Suppression of Th2 and Tfh immune reactions by Nr4a receptors in mature T reg cells. J Exp Med 2015, 212(10): 1623-1640.

8. DuPage M, Chopra G, Quiros J, Rosenthal WL, Morar MM, Holohan D, et al. The chromatin-modifying enzyme Ezh2 is critical for the maintenance of regulatory T cell identity after activation. Immunity 2015, 42(2): 227-238.

9. Shrestha S, Yang K, Guy C, Vogel P, Neale G, Chi H. Treg cells require the phosphatase PTEN to restrain TH1 and TFH cell responses. Nat Immunol 2015, 16(2): 178-187.

10. Huynh A, DuPage M, Priyadharshini B, Sage PT, Quiros J, Borges CM, et al. Control of PI(3) kinase in Treg cells maintains homeostasis and lineage stability. Nat Immunol 2015, 16(2): 188-196.

11. Overacre-Delgoffe AE, Chikina M, Dadey RE, Yano H, Brunazzi EA, Shayan G, et al. Interferon-gamma Drives Treg Fragility to Promote Anti-tumor Immunity. Cell 2017, 169(6): 1130-1141 e1111. 
12. Yue X, Trifari S, Aijo T, Tsagaratou A, Pastor WA, Zepeda-Martinez JA, et al. Control of Foxp3 stability through modulation of TET activity. J Exp Med 2016, 213(3): 377-397.

13. Floess S, Freyer J, Siewert C, Baron U, Olek S, Polansky J, et al. Epigenetic control of the foxp3 locus in regulatory T cells. PLoS Biol 2007, 5(2): e38.

14. Tahiliani M, Koh KP, Shen $\mathrm{Y}$, Pastor WA, Bandukwala H, Brudno $\mathrm{Y}$, et al. Conversion of 5methylcytosine to 5-hydroxymethylcytosine in mammalian DNA by MLL partner TET1. Science 2009, 324(5929): 930-935.

15. Iyer LM, Tahiliani M, Rao A, Aravind L. Prediction of novel families of enzymes involved in oxidative and other complex modifications of bases in nucleic acids. Cell cycle 2009, 8(11): 1698-1710.

16. Ito S, Shen L, Dai Q, Wu SC, Collins LB, Swenberg JA, et al. Tet proteins can convert 5-methylcytosine to 5-formylcytosine and 5-carboxylcytosine. Science 2011, 333(6047): 1300-1303.

17. He YF, Li BZ, Li Z, Liu P, Wang Y, Tang Q, et al. Tet-mediated formation of 5-carboxylcytosine and its excision by TDG in mammalian DNA. Science 2011, 333(6047): 1303-1307.

18. Ko M, Huang Y, Jankowska AM, Pape UJ, Tahiliani M, Bandukwala HS, et al. Impaired hydroxylation of 5-methylcytosine in myeloid cancers with mutant TET2. Nature 2010, 468(7325): 839-843.

19. Wu X, Zhang Y. TET-mediated active DNA demethylation: mechanism, function and beyond. Nat Rev Genet 2017, 18(9): 517-534.

20. Pastor WA, Rao A. TETonic shift: Biological roles of TET proteins in DNA demethylation and transcription. Nat Rev Mol Cell Biol 2013.

21. Tsagaratou A, Lio CJ, Yue X, Rao A. TET Methylcytosine Oxidases in T Cell and B Cell Development and Function. Frontiers in immunology 2017, 8: 220.

22. An J, Gonzalez-Avalos E, Chawla A, Jeong M, Lopez-Moyado IF, Li W, et al. Acute loss of TET function results in aggressive myeloid cancer in mice. Nature communications 2015, 6: 10071.

23. Lio CW, Zhang J, Gonzalez-Avalos E, Hogan PG, Chang X, Rao A. Tet2 and Tet3 cooperate with Blineage transcription factors to regulate DNA modification and chromatin accessibility. eLife 2016, 5.

24. Orlanski S, Labi V, Reizel Y, Spiro A, Lichtenstein $M$, Levin-Klein $R$, et al. Tissue-specific DNA demethylation is required for proper B-cell differentiation and function. Proc Natl Acad Sci U S A 2016, 113(18): 5018-5023.

25. Tsagaratou A, Gonzalez-Avalos E, Rautio S, Scott-Browne JP, Togher S, Pastor WA, et al. TET proteins regulate the lineage specification and TCR-mediated expansion of iNKT cells. Nat Immunol 2017, 18(1): 45-53.

26. Yang R, Qu C, Zhou Y, Konkel JE, Shi S, Liu Y, et al. Hydrogen Sulfide Promotes Tet1- and Tet2Mediated Foxp3 Demethylation to Drive Regulatory $\mathrm{T}$ Cell Differentiation and Maintain Immune Homeostasis. Immunity 2015, 43(2): 251-263.

27. Rubtsov YP, Rasmussen JP, Chi EY, Fontenot J, Castelli L, Ye X, et al. Regulatory T cell-derived interleukin-10 limits inflammation at environmental interfaces. Immunity 2008, 28(4): 546-558.

28. Delgoffe GM, Woo SR, Turnis ME, Gravano DM, Guy C, Overacre AE, et al. Stability and function of regulatory $T$ cells is maintained by a neuropilin-1-semaphorin-4a axis. Nature 2013, 501(7466): 252256. 
29. Yadav M, Louvet C, Davini D, Gardner JM, Martinez-Llordella M, Bailey-Bucktrout S, et al. Neuropilin-1 distinguishes natural and inducible regulatory $\mathrm{T}$ cells among regulatory $\mathrm{T}$ cell subsets in vivo. $J$ Exp Med 2012, 209(10): 1713-1722, S1711-1719.

30. Weiss JM, Bilate AM, Gobert M, Ding Y, Curotto de Lafaille MA, Parkhurst CN, et al. Neuropilin 1 is expressed on thymus-derived natural regulatory $\mathrm{T}$ cells, but not mucosa-generated induced Foxp3+ $\mathrm{T}$ reg cells. J Exp Med 2012, 209(10): 1723-1742, S1721.

31. Thornton AM, Korty PE, Tran DQ, Wohlfert EA, Murray PE, Belkaid Y, et al. Expression of Helios, an Ikaros transcription factor family member, differentiates thymic-derived from peripherally induced Foxp3+ T regulatory cells. J Immunol 2010, 184(7): 3433-3441.

32. Gottschalk RA, Corse E, Allison JP. Expression of Helios in peripherally induced Foxp3+ regulatory T cells. J Immunol 2012, 188(3): 976-980.

33. Singh K, Hjort M, Thorvaldson L, Sandler S. Concomitant analysis of Helios and Neuropilin-1 as a marker to detect thymic derived regulatory T cells in naive mice. Scientific reports 2015, 5: 7767.

34. Schneider MA, Meingassner JG, Lipp M, Moore HD, Rot A. CCR7 is required for the in vivo function of CD4+ CD25+ regulatory T cells. J Exp Med 2007, 204(4): 735-745.

35. Pierson W, Cauwe B, Policheni A, Schlenner SM, Franckaert D, Berges J, et al. Antiapoptotic Mcl-1 is critical for the survival and niche-filling capacity of Foxp3(+) regulatory T cells. Nat Immunol 2013, 14(9): 959-965.

36. Brunkow ME, Jeffery EW, Hjerrild KA, Paeper B, Clark LB, Yasayko SA, et al. Disruption of a new forkhead/winged-helix protein, scurfin, results in the fatal lymphoproliferative disorder of the scurfy mouse. Nature genetics 2001, 27(1): 68-73.

37. Choi JM, Shin JH, Sohn MH, Harding MJ, Park JH, Tobiasova Z, et al. Cell-permeable Foxp3 protein alleviates autoimmune disease associated with inflammatory bowel disease and allergic airway inflammation. Proc Natl Acad Sci U S A 2010, 107(43): 18575-18580.

38. Ouyang W, Beckett O, Ma Q, Paik JH, DePinho RA, Li MO. Foxo proteins cooperatively control the differentiation of Foxp3+ regulatory T cells. Nat Immunol 2010, 11(7): 618-627.

39. Zheng Y, Josefowicz S, Chaudhry A, Peng XP, Forbush K, Rudensky AY. Role of conserved noncoding DNA elements in the Foxp3 gene in regulatory T-cell fate. Nature 2010, 463(7282): 808-812.

40. Ohkura N, Hamaguchi M, Morikawa H, Sugimura K, Tanaka A, Ito $\mathrm{Y}$, et al. T cell receptor stimulationinduced epigenetic changes and Foxp3 expression are independent and complementary events required for Treg cell development. Immunity 2012, 37(5): 785-799.

41. Meisel M, Hinterleitner R, Pacis A, Chen L, Earley ZM, Mayassi T, et al. Microbial signals drive preleukaemic myeloproliferation in a Tet2-deficient host. Nature 2018, 557(7706): 580-584.

42. Ciccia A, Elledge SJ. The DNA damage response: making it safe to play with knives. Mol Cell 2010, 40(2): 179-204.

43. Srinivas S, Watanabe T, Lin CS, William CM, Tanabe $\mathrm{Y}$, Jessell TM, et al. Cre reporter strains produced by targeted insertion of EYFP and ECFP into the ROSA26 locus. BMC developmental biology 2001, 1: 4 . 
44. Wu D, Luo Y, Guo W, Niu Q, Xue T, Yang F, et al. Lkb1 maintains Treg cell lineage identity. Nature communications 2017, 8: 15876.

45. Hori S, Nomura T, Sakaguchi S. Control of regulatory T cell development by the transcription factor Foxp3. Science 2003, 299(5609): 1057-1061.

46. Fontenot JD, Gavin MA, Rudensky AY. Foxp3 programs the development and function of CD4+CD25+ regulatory T cells. Nat Immunol 2003, 4(4): 330-336.

47. Bandukwala HS, Wu Y, Feuerer M, Chen Y, Barboza B, Ghosh S, et al. Structure of a domain-swapped FOXP3 dimer on DNA and its function in regulatory T cells. Immunity 2011, 34(4): 479-491.

48. Hill JA, Feuerer M, Tash K, Haxhinasto S, Perez J, Melamed R, et al. Foxp3 transcription-factordependent and -independent regulation of the regulatory $\mathrm{T}$ cell transcriptional signature. Immunity 2007, 27(5): 786-800.

49. Sawant DV, Vignali DA. Once a Treg, always a Treg? Immunol Rev 2014, 259(1): 173-191.

50. Nair VS, Oh KI. Down-regulation of Tet2 prevents TSDR demethylation in IL2 deficient regulatory T cells. Biochemical and biophysical research communications 2014, 450(1): 918-924.

51. Ko M, An J, Pastor WA, Koralov SB, Rajewsky K, Rao A. TET proteins and 5-methylcytosine oxidation in hematological cancers. Immunol Rev 2015, 263(1): 6-21.

52. Li Z, Cai X, Cai CL, Wang J, Zhang W, Petersen BE, et al. Deletion of Tet2 in mice leads to dysregulated hematopoietic stem cells and subsequent development of myeloid malignancies. Blood 2011, 118(17): 4509-4518.

53. Moran-Crusio K, Reavie L, Shih A, Abdel-Wahab O, Ndiaye-Lobry D, Lobry C, et al. Tet2 loss leads to increased hematopoietic stem cell self-renewal and myeloid transformation. Cancer Cell 2011, 20(1): 11-24.

54. Rasmussen KD, Jia G, Johansen JV, Pedersen MT, Rapin N, Bagger FO, et al. Loss of TET2 in hematopoietic cells leads to DNA hypermethylation of active enhancers and induction of leukemogenesis. Genes Dev 2015, 29(9): 910-922.

55. Ko M, Bandukwala HS, An J, Lamperti ED, Thompson EC, Hastie R, et al. Ten-Eleven-Translocation 2 (TET2) negatively regulates homeostasis and differentiation of hematopoietic stem cells in mice. Proc Natl Acad Sci U S A 2011, 108(35): 14566-14571.

56. Quivoron C, Couronne L, Della Valle V, Lopez CK, Plo I, Wagner-Ballon O, et al. TET2 inactivation results in pleiotropic hematopoietic abnormalities in mouse and is a recurrent event during human lymphomagenesis. Cancer Cell 2011, 20(1): 25-38.

57. Bachman M, Uribe-Lewis S, Yang X, Williams M, Murrell A, Balasubramanian S. 5Hydroxymethylcytosine is a predominantly stable DNA modification. Nature chemistry 2014, 6(12): 1049-1055.

58. Bachman M, Uribe-Lewis S, Yang X, Burgess HE, lurlaro M, Reik W, et al. 5-Formylcytosine can be a stable DNA modification in mammals. Nature chemical biology 2015, 11(8): 555-557.

59. Otani J, Kimura H, Sharif J, Endo TA, Mishima Y, Kawakami T, et al. Cell cycle-dependent turnover of 5-hydroxymethyl cytosine in mouse embryonic stem cells. PLoS One 2013, 8(12): e82961. 
60. Park Y, Jin HS, Lopez J, Elly C, Kim G, Murai M, et al. TSC1 regulates the balance between effector and regulatory T cells. The Journal of clinical investigation 2013, 123(12): 5165-5178.

61. Kim D, Pertea G, Trapnell C, Pimentel H, Kelley R, Salzberg SL. TopHat2: accurate alignment of transcriptomes in the presence of insertions, deletions and gene fusions. Genome biology 2013, 14(4): R36.

62. Liao Y, Smyth GK, Shi W. featureCounts: an efficient general purpose program for assigning sequence reads to genomic features. Bioinformatics 2014, 30(7): 923-930.

63. Love MI, Huber W, Anders S. Moderated estimation of fold change and dispersion for RNA-seq data with DESeq2. Genome biology 2014, 15(12): 550.

64. Bolotin DA, Poslavsky S, Mitrophanov I, Shugay M, Mamedov IZ, Putintseva EV, et al. MiXCR: software for comprehensive adaptive immunity profiling. Nat Methods 2015, 12(5): 380-381.

\section{Figure Legends}

Figure 1. Phenotypic analysis of mice with Treg-specific deletion of Tet2 and Tet3.

a. Survival curves for control WT and Tet2/3 ${ }^{f / f l} F o x p 3^{\text {Cre }} D K O$ mice $(n=28)$. b. Total cell numbers in spleen, peripheral lymph nodes ( $\mathrm{pLN}$ ) and mesenteric lymph nodes $(\mathrm{mLN})$ of WT and Tet2/3 ${ }^{\text {fl/fl}}$ Foxp3 ${ }^{\text {Cre }}$ DKO mice (1316 weeks old, $\mathrm{n}=9$ ). c. Percentages (left panel) and cell numbers (right panel) of $\mathrm{CD} 4^{+}$and $\mathrm{CD} 8^{+} \mathrm{T}$ cells in the spleen and pLN from WT and Tet2/3 ${ }^{f / f t}$ Foxp3 $^{\text {Cre }}$ DKO mice (13-16 weeks old, $\mathrm{n}=9$ ). d. Representative flow cytometry analysis of CD62L and CD44 expression in CD4 ${ }^{+}$Foxp3 ${ }^{-} \mathrm{T}$ cells from spleen (upper panels) and pLN (lower panels). e. Representative flow cytometry analysis of CD62L and CD44 expression in CD8 ${ }^{+} \mathrm{T}_{\text {cells from }}$ spleen (upper panels) and pLN (lower panels). Statistical analysis was performed using two-tailed unpaired student's $t$ test $\left({ }^{*} P<0.05\right.$, $\left.{ }^{* *} P<0.01,{ }^{* * *} P<0.001,{ }^{* * *} P<0.0001\right)$. Data are mean \pm S.D. from at least three independent experiments.

\section{Figure 2. Characterization of Tet2/3-deficient Treg cells.}

a. Representative flow cytometry analyses of the percentage of Treg cells (\% of Foxp $3^{+}$cells in gated CD4 ${ }^{+} \mathrm{T}$ cells) in spleen and pLN from WT and Tet2/3 ${ }^{f / f l} F o x p 3^{C r e} D K O$ mice (13-16 weeks old). b. Quantification of the percentages (left panel) and cell numbers (right panel) of Treg cells in spleen, pLN and mLN from WT and Tet2/3 ${ }^{f / f t}$ Foxp3 ${ }^{\text {Cre }}$ DKO mice (13-16 weeks old, $\mathrm{n}=9$ ). c-f. Flow cytometry analysis of Tet2/3-deficient Treg cells from spleen and pLN for the expression of CD25 and Nrp1 (c); Helios, ICOS, CD103, GITR, CTLA4, PD1 and CD127 (d); CD62L versus CD44 (e); and CD69 (f). Shown are WT CD4 ${ }^{+}$T cells (shaded grey); WT Tregs (black line); DKO Tregs (red line). Statistical analysis was performed using two-tailed unpaired student's t test $\left({ }^{*} \mathrm{P}<0.05,{ }^{* *} \mathrm{P}<0.01,{ }^{* * *} \mathrm{P}<0.001,{ }^{* * *} \mathrm{P}<0.0001\right)$. Data are mean $\pm S . D$. from at least three independent experiments.

Figure 3. DNA methylation status of Foxp3 CNS1 and CNS2 in WT and Tet2/3 ${ }^{f / f l}$ Foxp $3^{\text {Cre }}$ DKO Treg cells. a-b. DNA methylation status of Foxp3 CNS1 and CNS2. Graphs depict the percentage of $5 \mathrm{mC}+5 \mathrm{hmC}$ determined by BS-seq in peripheral Tregs in: (a) 4 CpGs in Foxp3 CNS1, and (b) 11 CpGs in Foxp3 CNS2, (c) 4 CpGs in II2ra intron 1a, (d) 7 CpGs in Tnfrsf18 exon 5, (e) 6 CpGs in Ikzf4 intron $1 b$ and (f) 5 CpGs in Ctla4 exon 2. Error bars show mean \pm S.D. of thousands of sequencing reads from two independent experiments. Wild type (WT) Treg cells (8-10 weeks old) are shown in black, CD4 ${ }^{\text {Cre }}$ mediated Tet2/3 DKO Treg cells (3-4 
weeks old) are shown in red ${ }^{12}$ and Foxp $3^{\text {Cre }}$ mediated Tet2/3 DKO Treg cells (8-10 weeks old) are shown in blue.

\section{Figure 4. RNA-seq analysis for Treg cells isolated from WT or Tet2/3 ${ }^{\text {fl/fl}}$ Foxp $3^{\text {Cre }}$ DKO mice.}

a. Mean average (MA) plot of genes differentially expressed in Tet2/3 DKO Tregs (14-weeks old, isolated from pooled spleen and pLNs) relative to their expression in WT Treg cells. b. IPA analysis of canonical pathways for differentially expressed genes in Tet2/3 DKO Treg cells. Green, categories related to DNA repair, DNA damage and cell cycle; blue, categories related to immune cell function; orange, category related to cancer. c. Heatmap for the expression of selected genes encoding cell cycle regulators with differential expression. The color gradient indicates Log2 Fold Change (DKO/WT). d. Left panel, Representative flow cytometry analysis of BrdU incorporation in CD4 ${ }^{+}$Foxp3 ${ }^{+}$Treg cells in spleen and pLN from WT and Tet2/3 ${ }^{f / f l}$ Foxp $3^{\text {Cre }}$ DKO mice (10 weeks old). The gates show the percentage of cells with BrdU incorporation. Right panel, Quantification of the frequency of $\mathrm{CD}^{+}{ }^{+}$Foxp3 ${ }^{+}$Treg cells that incorporated BrdU. e. Heatmaps showing expression (row z score of log2 TPM values) of Tfh-related genes in WT and DKO Tregs (left panel) and of Tfh and Th17 related genes for WT and DKO CD4 ${ }^{+}$Foxp3 ${ }^{-}$cells (right panel). $\mathbf{f}$. Flow cytometry analysis of CXCR5 ${ }^{+} \mathrm{PD}-1^{+}$Tfh cells (gated on $\mathrm{CD}^{+}{ }^{\mathrm{TCR}} \beta^{+} \mathrm{T}$ cells) in the spleen and $\mathrm{mLN}$ of WT and Tet2/3 ${ }^{\text {fl/fl }}$ Foxp3 ${ }^{\text {Cre }}$ DKO mice (13-16 weeks old). $\mathbf{g}$. Flow cytometry analysis of $\mathrm{GL} 7^{+} \mathrm{CD} 95^{+}$germinal center B cells (gated on $\mathrm{CD} 19^{+} \mathrm{B}$ cells) in the spleen and $\mathrm{mLN}$ of WT and Tet2/3 ${ }^{\text {fl/fl}}$ Foxp3 ${ }^{\text {Cre }}$ DKO mice (13-16 weeks old). Statistical analysis was performed using twotailed unpaired student's t test $\left({ }^{\star} \mathrm{P}<0.05,{ }^{* *} \mathrm{P}<0.01,{ }^{* \star *} \mathrm{P}<0.001,{ }^{* * *} \mathrm{P}<0.0001\right)$. Data are mean $\pm \mathrm{S}$.D. from two to three independent experiments.

\section{Figure 5. The presence of WT Treg cells fails to rescue the inflammatory phenotype of Tet2/3/fll Foxp $3^{\text {Cre }}$ DKO mice.}

a. Survival curves for control WT $(n=9)$ and Tet2 $/ 3^{f / f t} F o x p 3^{W T / C r e}$ heterozygous female $(n=9)$ mice. b. Total cell numbers in spleen from WT and Tet2/3/f/fl Foxp3 ${ }^{W T / C r e}$ heterozygous female mice (15-30 weeks old, $\left.\mathrm{n}=5\right)$. c. Schematic illustration for the generation of mixed bone marrow chimeras. The flow cytometry plots show the ratios of WT CD45.1 $1^{+}$congenic bone marrow cells and co-transferred CD45.2 ${ }^{+}$WT or Tet2/3 DKO bone marrow cells immediately prior to transfer. d. Total cell numbers in spleen from WT and Tet2/3 DKO mixed bone marrow chimeras with splenomegaly $(n=7)$ 18-20 weeks after transfer. e. Representative flow cytometry analysis for WT and DKO mixed bone marrow chimeras 18-20 weeks after transfer. $\mathbf{f}$. The graphs from left to right show the quantifications for the percentage of $\mathrm{CD} 45.2^{+}$cells, the percentage of $\mathrm{CD} 4^{+}$and $\mathrm{CD} 8^{+}$cells within the CD45.2 $2^{+}$cells and the percentage of Foxp $3^{+}$cells within the CD $45.2^{+}$CD $4^{+}$cells $(n=7)$. Statistical analysis was performed using two-tailed unpaired student's $t$ test $\left({ }^{*} P<0.05,{ }^{* *} P<0.01,{ }^{* *} P<0.001\right.$, $\left.{ }^{* \star * *} \mathrm{P}<0.0001\right)$.

\section{Figure 6. Fate mapping experiments show that Tet2/3 DKO Treg cells are less stable than Treg cells from heterozygous littermates}

a. Representative lineage tracing of Treg cells in spleen and $\mathrm{mLN}$ from littermate mice of Tet2 $^{+/ f l}$ Tet3 $^{\text {fl/fl}}$ Foxp3 $^{\text {YFP-Cre }}$ Rosa26 ${ }^{\text {YFP }}$ (Het) and Tet2/3 ${ }^{\text {fl/fl}}$ Foxp3 ${ }^{\text {YFP-Cre }}$ Rosa26 ${ }^{\text {YFP }}$ genotypes. Left panels, Contour plots showing that Rosa26 ${ }^{\mathrm{YFP}}$ is much brighter than, and so can be distinguished from, Foxp3 ${ }^{\text {YFP-Cre }}$. Right panels, The percentage of Foxp3-negative cells is much higher in sorted CD4 ${ }^{+}$Rosa26 ${ }^{\text {YFPhigh }}$ cells from

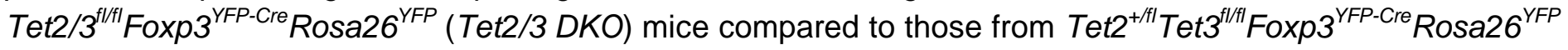
mice, indicating that Tet2/3 DKO Treg cells that had originally turned on Foxp3 and Cre from the Foxp $3^{\text {YFP-Cre }}$ locus later lose Foxp3 and become ex-Treg cells. b. Quantification of the percentage of Foxp3 ${ }^{\text {neg }}-$ Rosa26 $^{\text {YFPhigh }}$ cells as shown in a (11-12 weeks old, $n=3$ from three independent experiments). Statistical analysis was performed using two-tailed unpaired student's t test $\left({ }^{*} \mathrm{P}<0.05\right)$. 


\section{Figure 7. Transfer of total CD4 ${ }^{+} \mathrm{T}$ cells from ${\text { Tet } 2 / 3^{f / f l} \text { Foxp }}^{\text {Cre }}$ mice elicits disease in immunocompetent recipient mice.}

a. Schematic illustration for the transfer of total CD4 ${ }^{+} \mathrm{T}$ cells $\left(5 \times 10^{6}\right.$ cells $)$ from WT or Tet2/3 ${ }^{f / f l}$ Foxp $3^{\text {Cre }}$ DKO mice (14 weeks old) into immunocompetent congenic recipient mice ( $n=11$ recipient mice), the mice were analyzed 7-10 weeks after transfer. b. From left to right, the graphs show the numbers of total splenocytes and of transferred and expanded CD $45.2^{+}$cells, the fold increase in the number of transferred and expanded DKO CD $45.2^{+}$cells, the percentage of Foxp3 ${ }^{+}$cells in CD45.2 $2^{+}$cells after transfer, and the percentage of Foxp3 ${ }^{+}$ cells in CD45.2 $2^{+}$and CD45. $1^{+}$cells in each individual with connection lines. c. Representative flow cytometry analyses of the percentage of CD45.2 $2^{+} \mathrm{T}$ cells, the percentage of Foxp3 ${ }^{+}$cells in CD45.2 ${ }^{+}$cells (example 1 showing an expansion of Foxp3 ${ }^{+}$cells, example 2 showing a loss of Foxp3 ${ }^{+}$cells), the percentage of Foxp3 ${ }^{+}$ cells in CD45.1 $1^{+}$host cells, CD62L and CD44 expression in host Treg cells and CD4 ${ }^{+}$Foxp3 ${ }^{-}$cells. Statistical analysis was performed using two-tailed unpaired student's t test $\left({ }^{* * *} \mathrm{P}<0.001\right)$. 
Figure 1
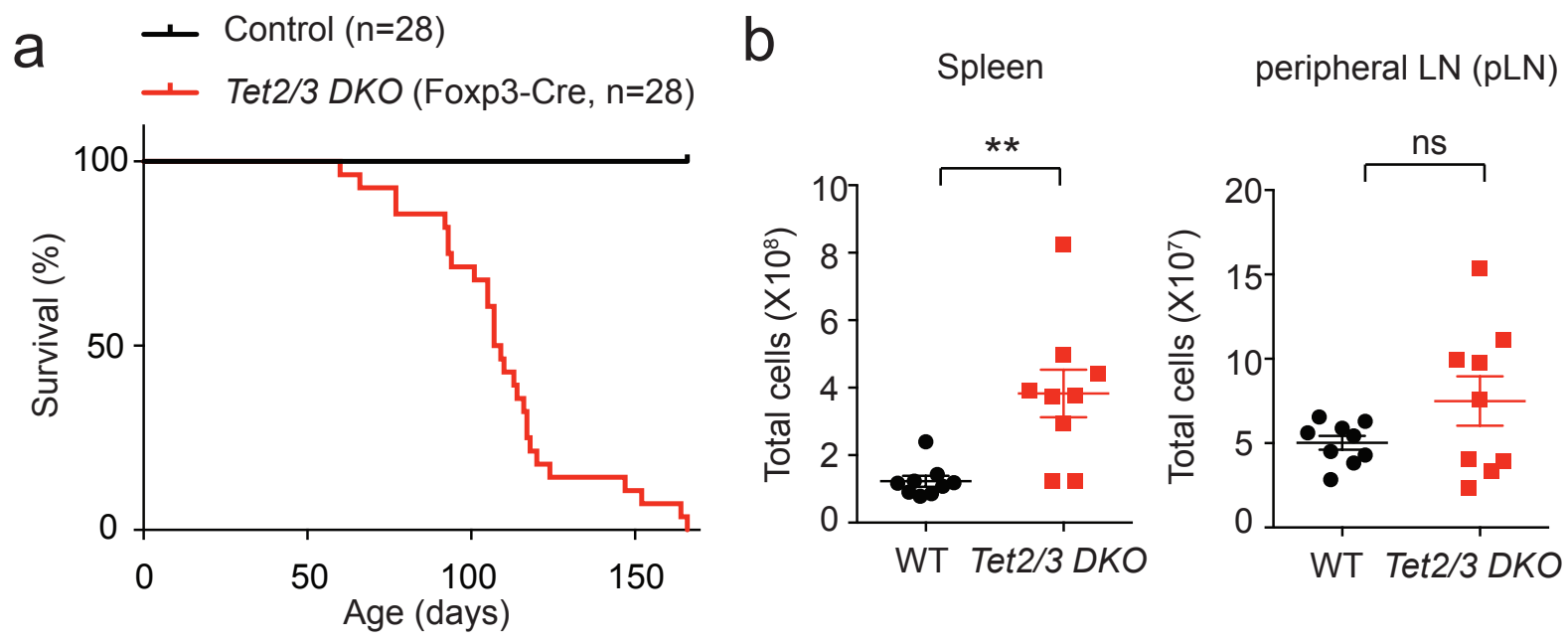

mesenteric LN (mLN)
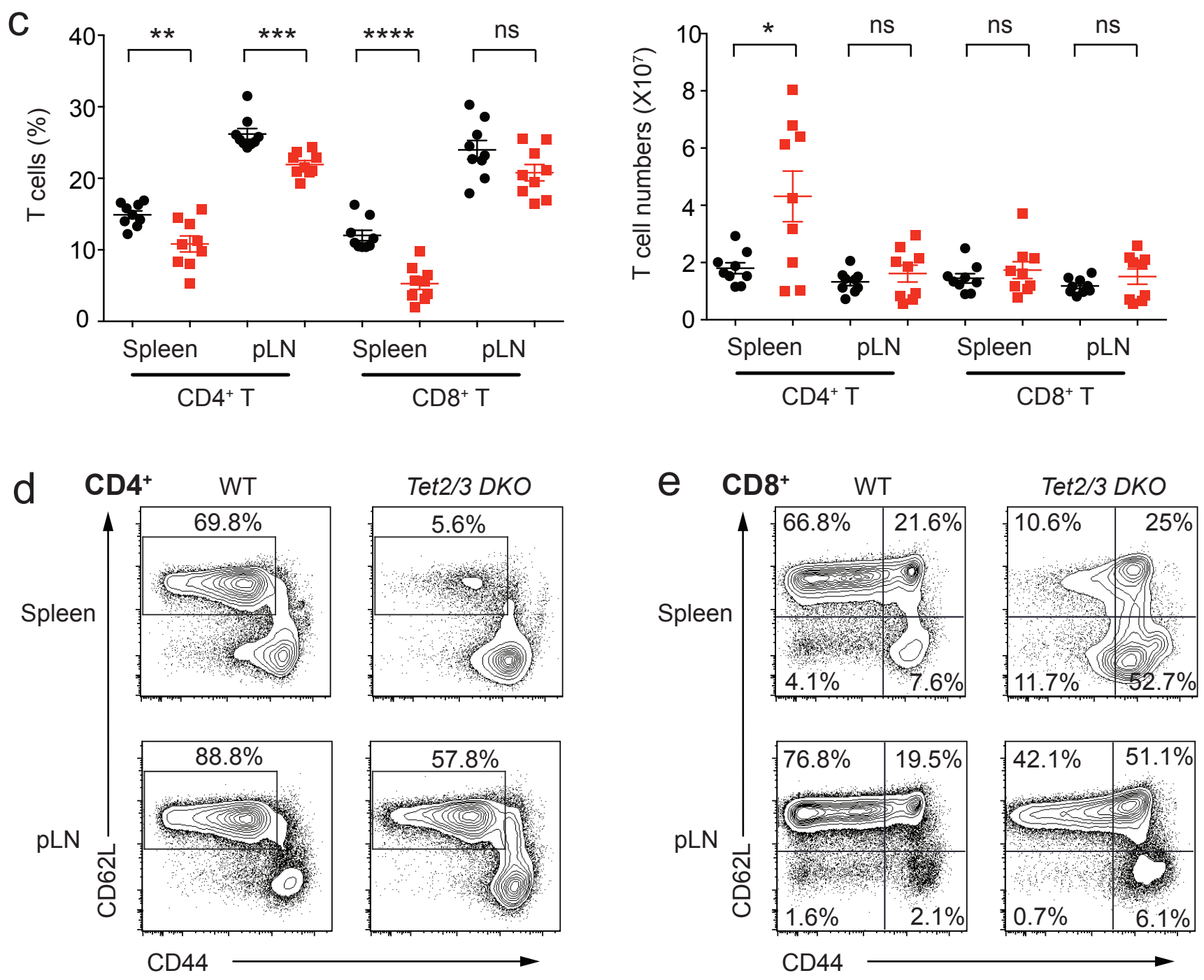
Figure 2 not certified by peer review) is the author/funder. All rights reserved. No reuse allowed without permission.
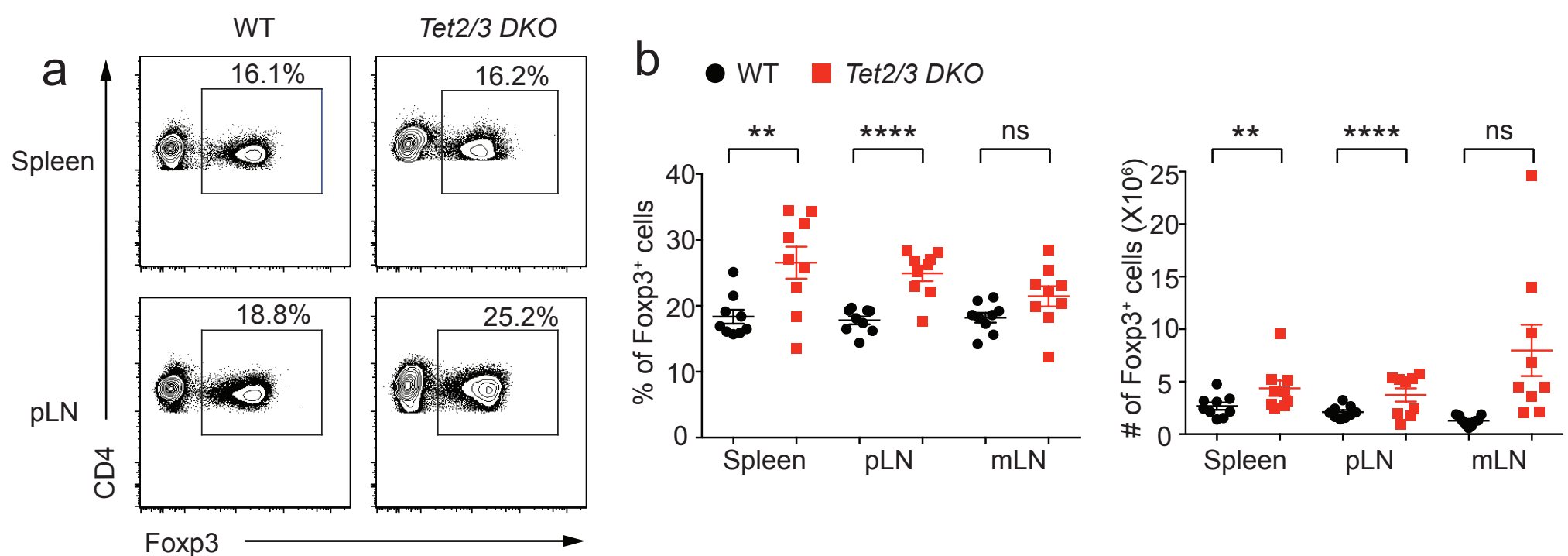

\section{C}
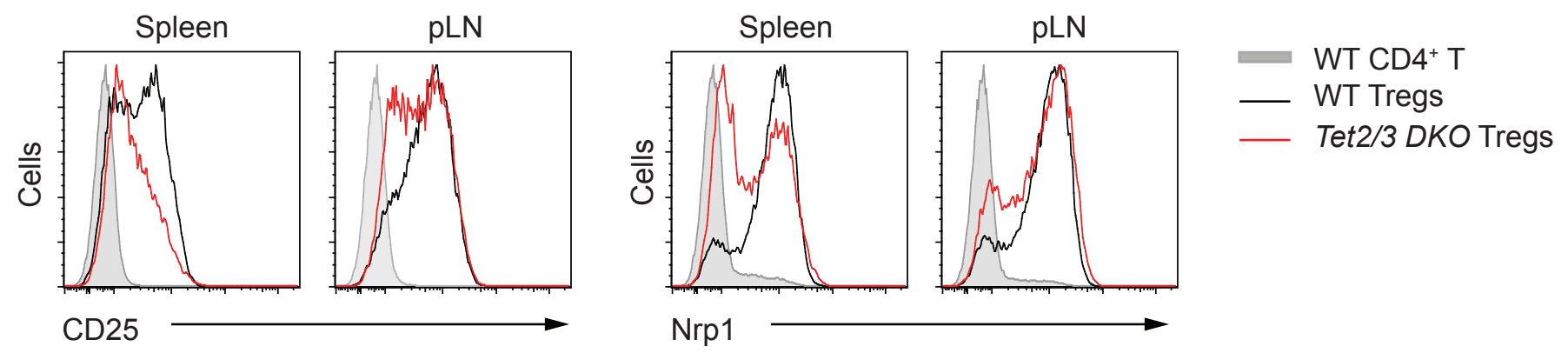

d $S p$
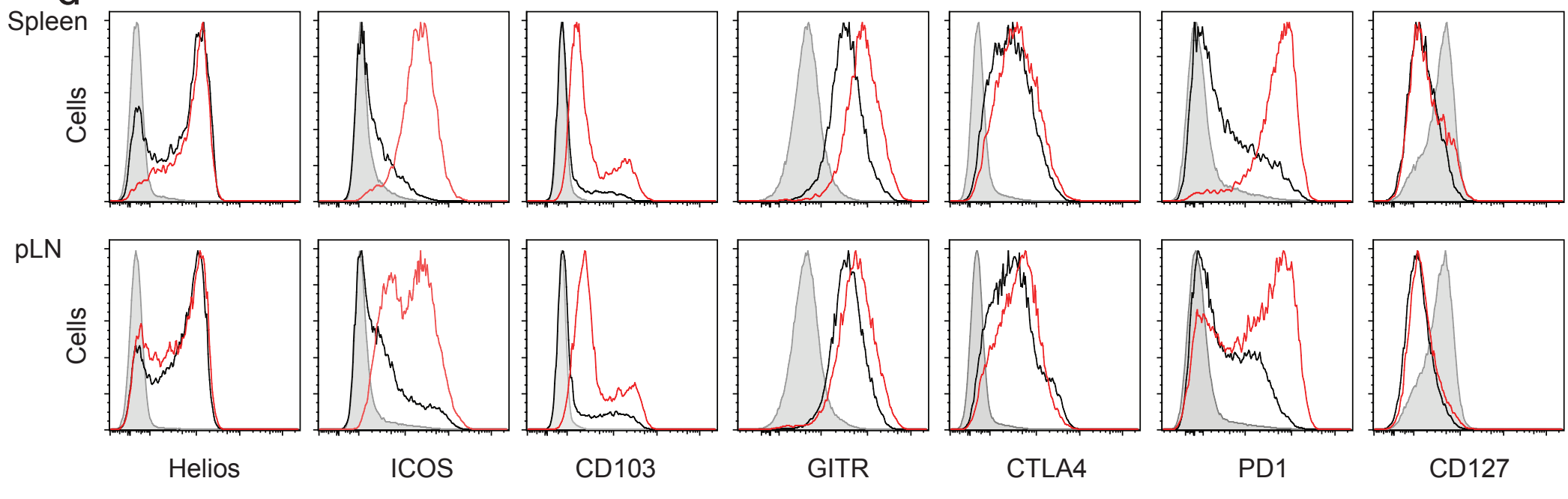

Helios

ICOS

CD103

GITR

CTLA4

PD1

CD127
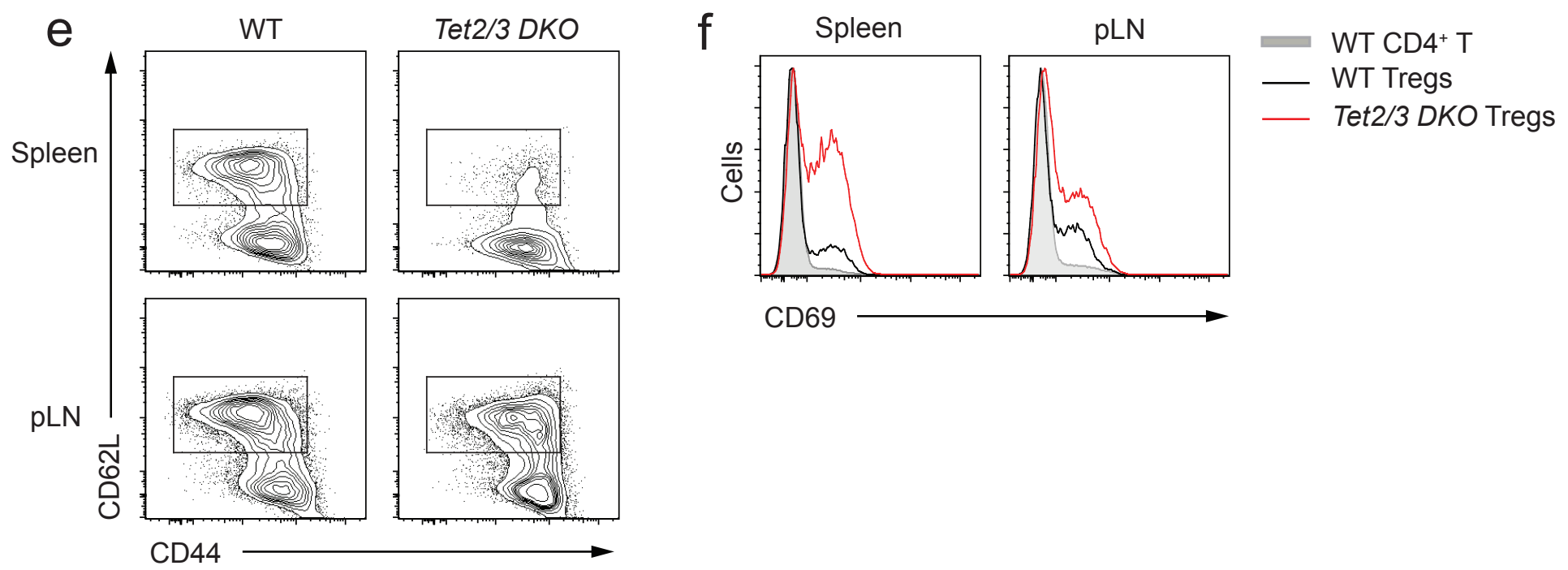


\section{Figure 3}

a

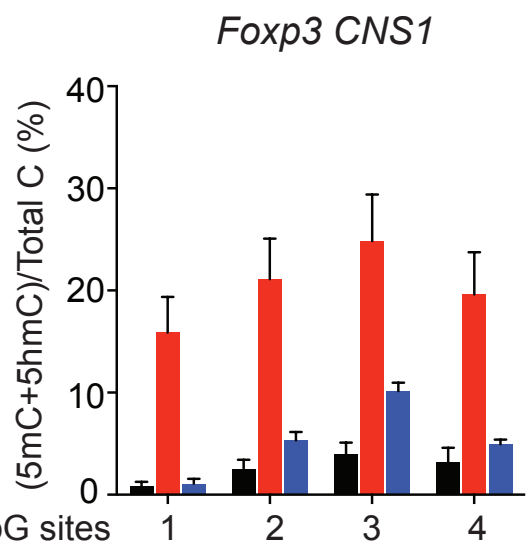

C

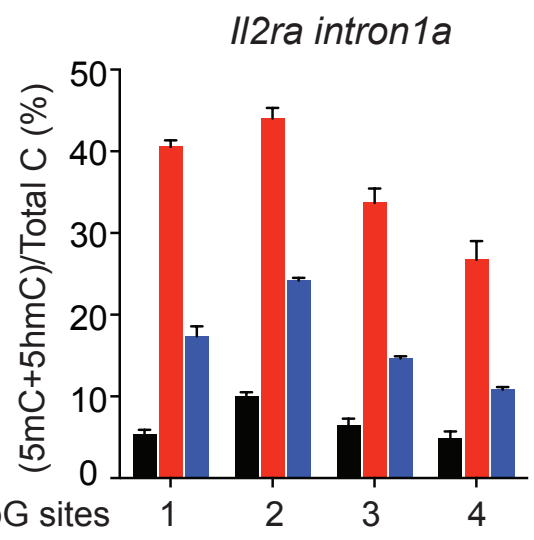

b

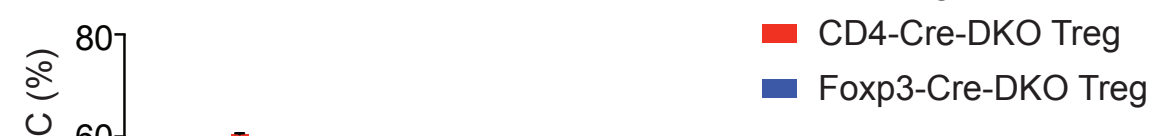

e

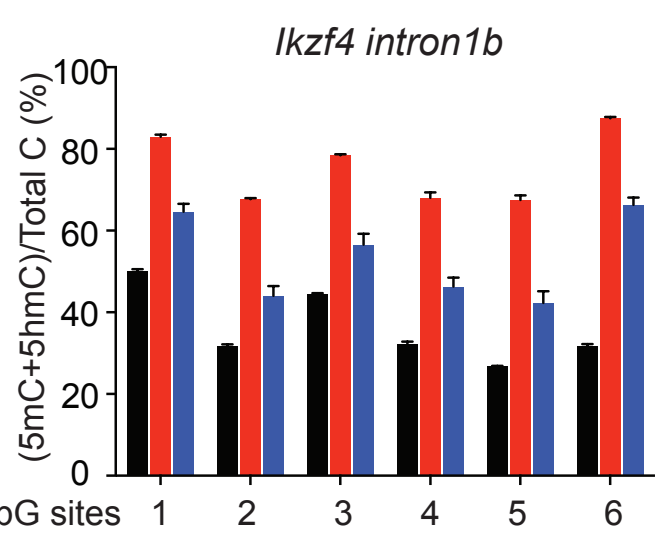

d

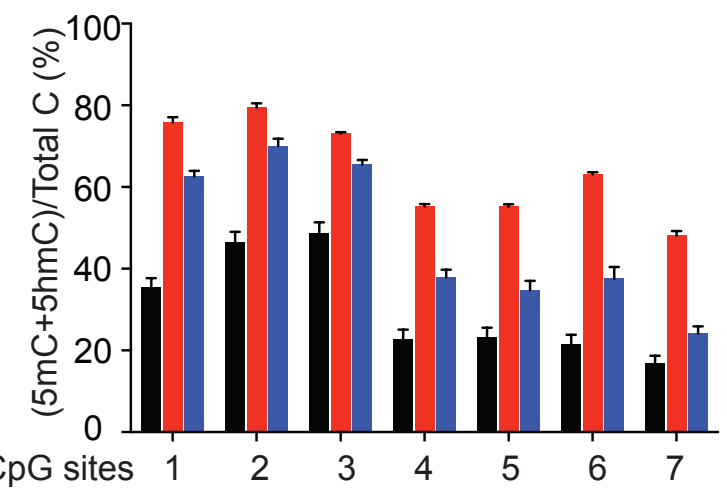

f Ctla4 exon2

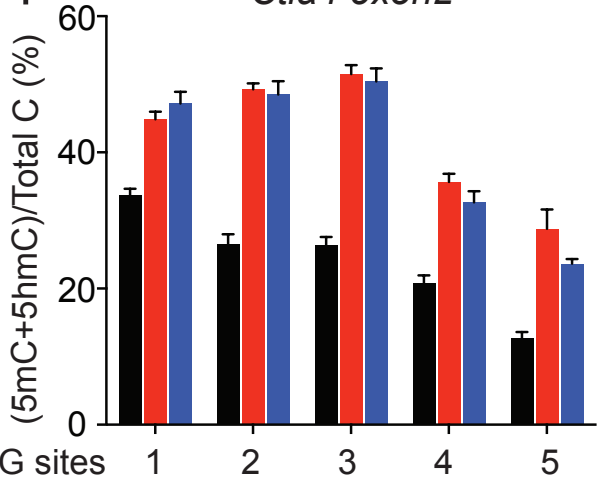


bioRxiv preprint doi: https://doi.org/10.1101/551093; this version posted February 15, 2019. The copyright holder for this preprint (which was
niqure 4
not certified by peer review) is the author/funder. All rights reserved. No reuse allowed without permission.

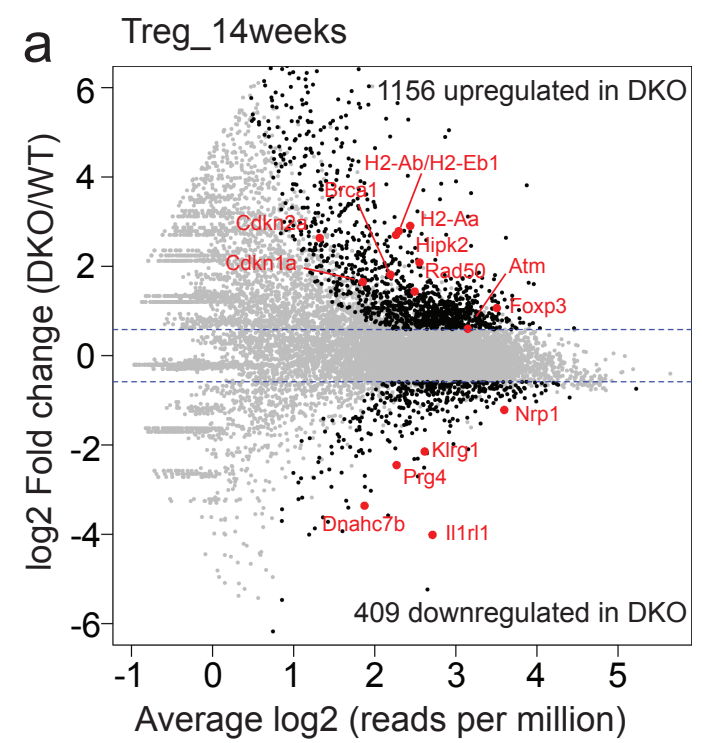

b
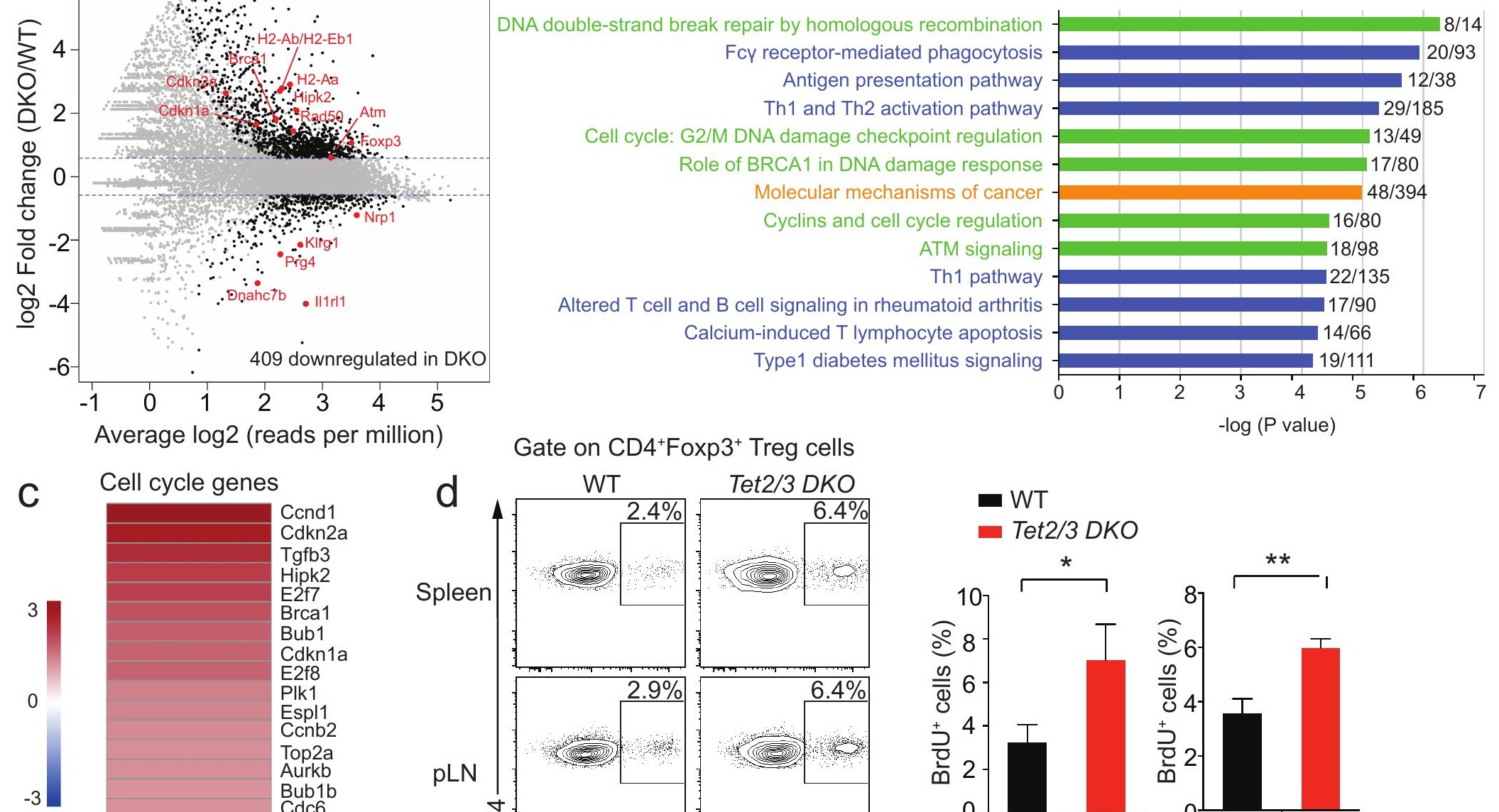

Cell cycle genes

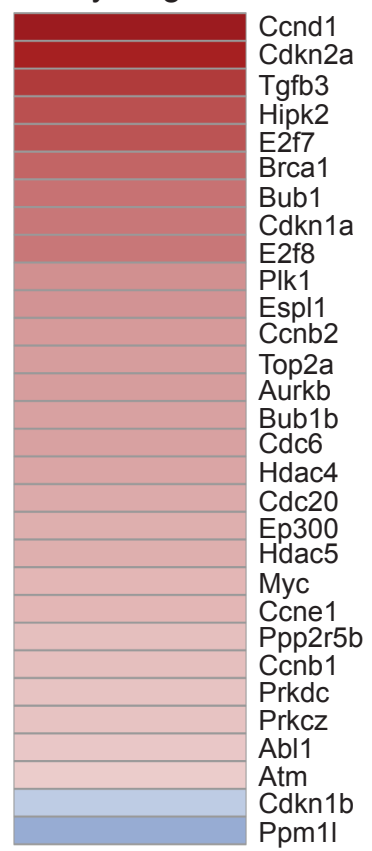

Log2(fold change)

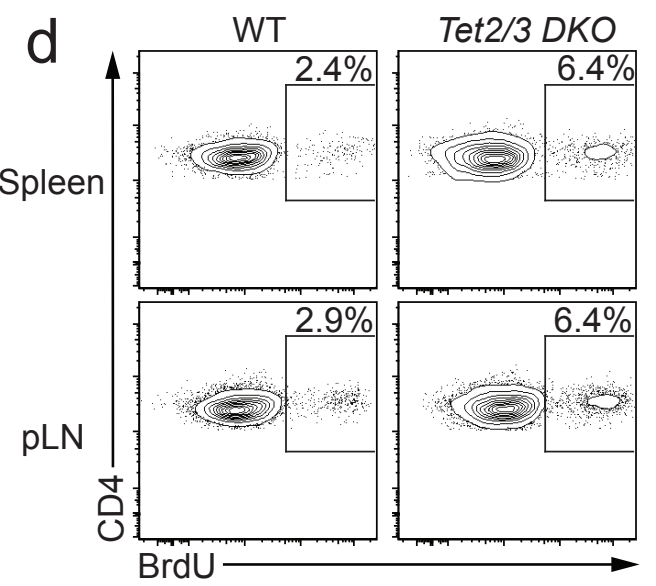

e Tfh related genes

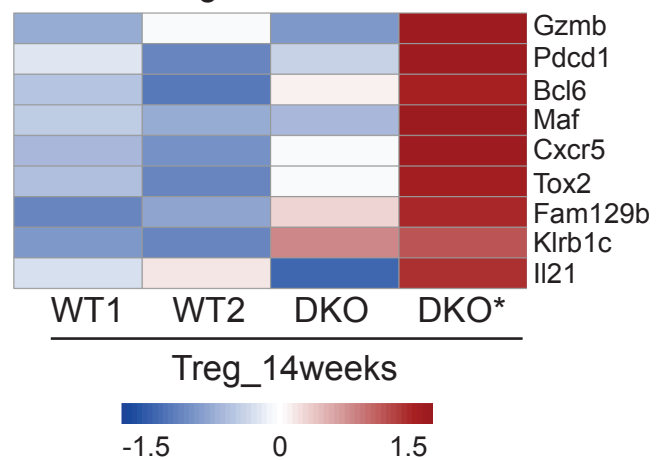

- WT
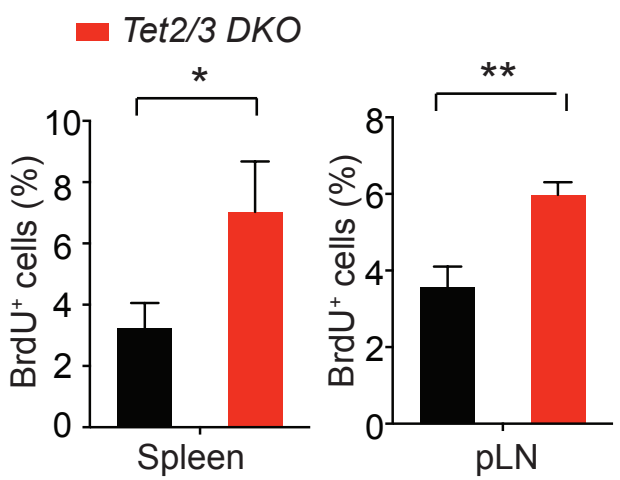

Tfh and Th17 related genes

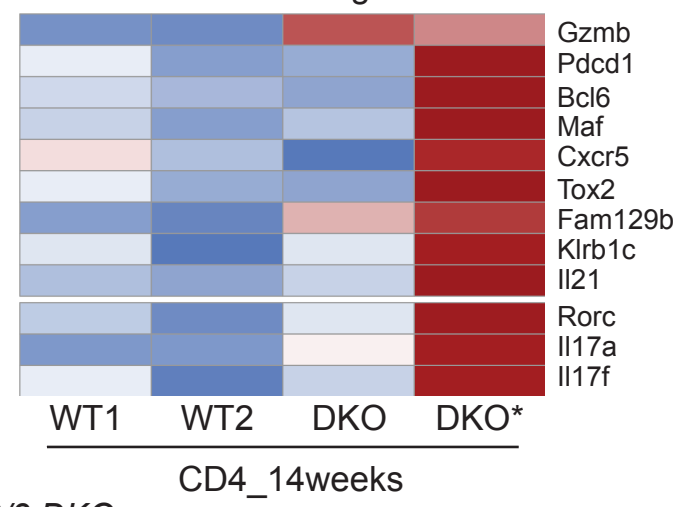

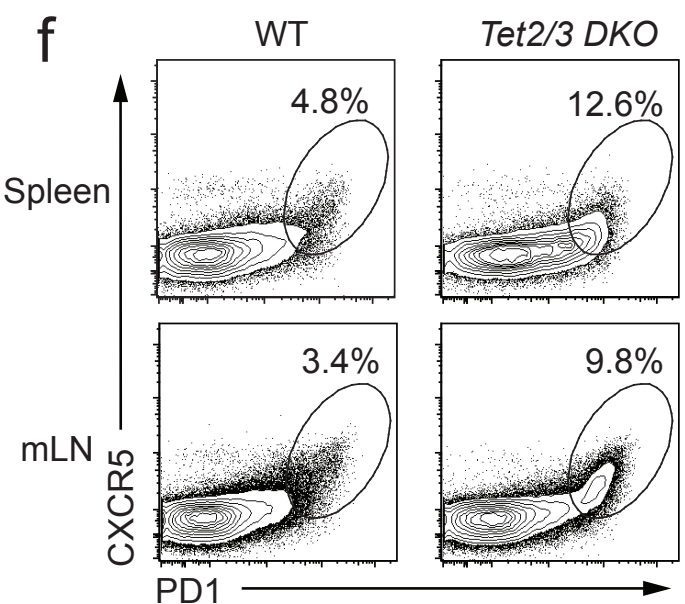

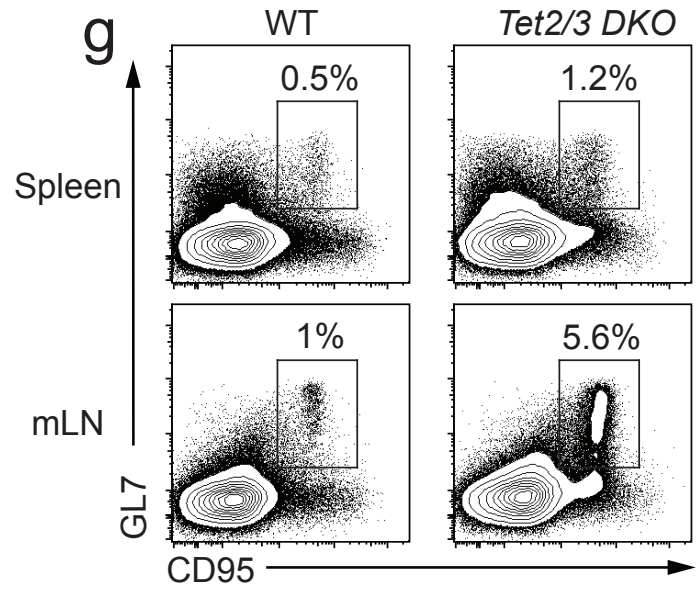


Fiaure bioRxiv preprint doi: https://doi.org/10.1101/551093; this version posted February 15, 2019. The copyright holder for this preprint (which was

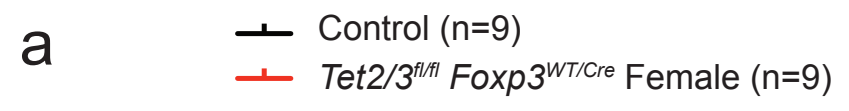

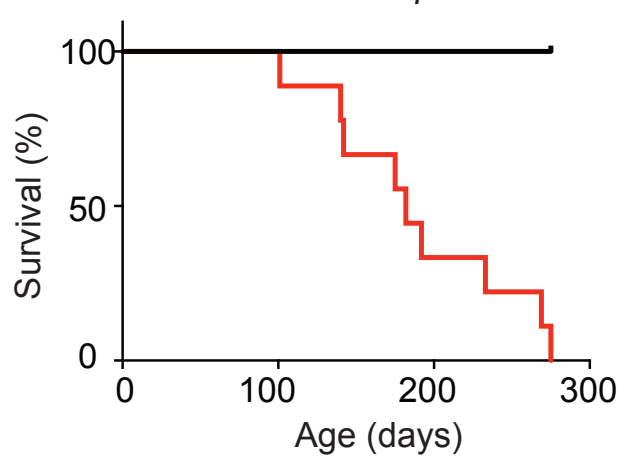

b 15-30 weeks old

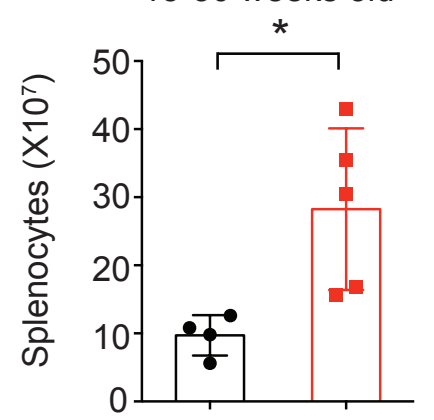

WT Control

Tet2/3 ${ }^{f / f / t}$ Foxp3 $3^{\text {WT/Cre }}$ Female

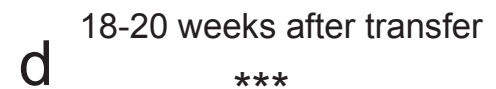

C WT Chimeras
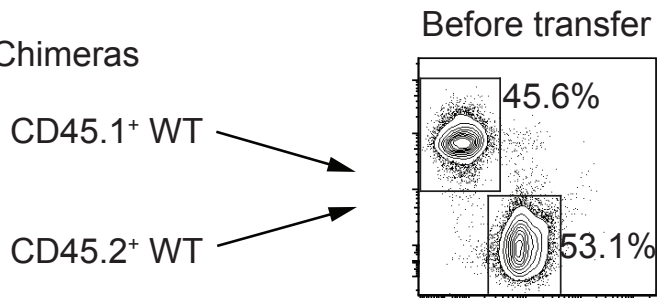

Lethally-irradiated mice

DKO Chimeras
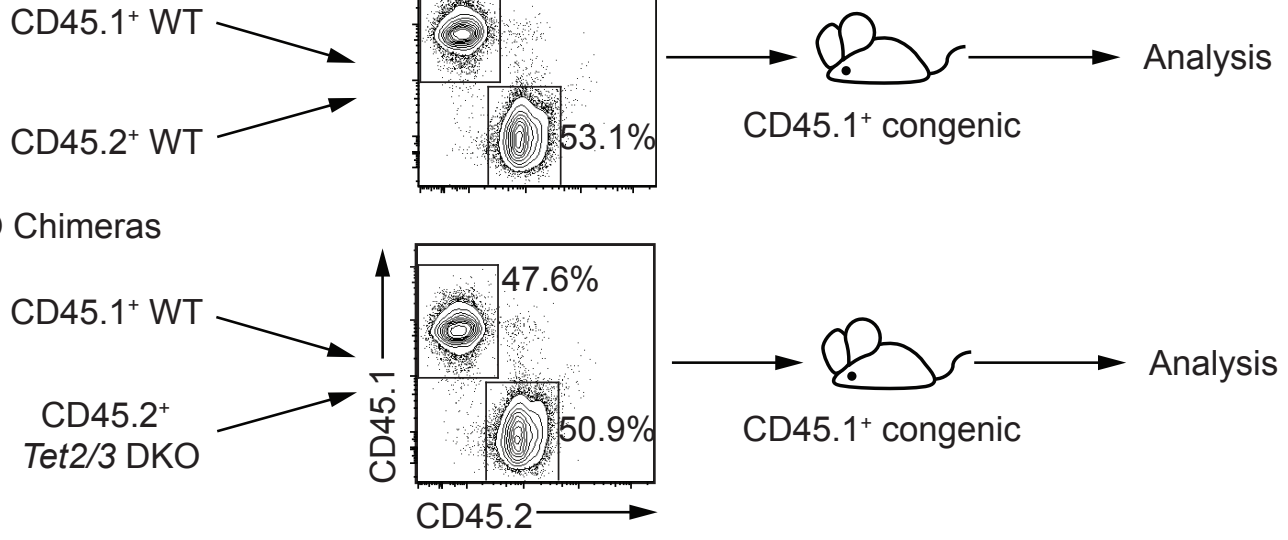

CD45.1+ congenic

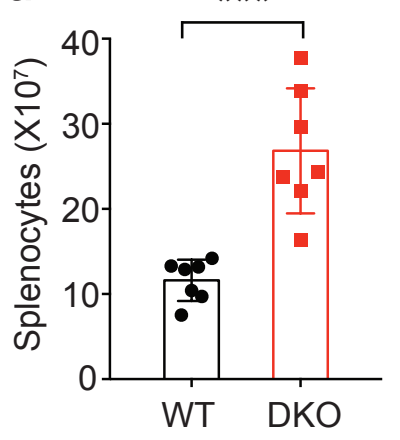

CD45.1 $1^{+}$congenic Analysis

e $\quad 18-20$ weeks after transfer

WT Chimeras
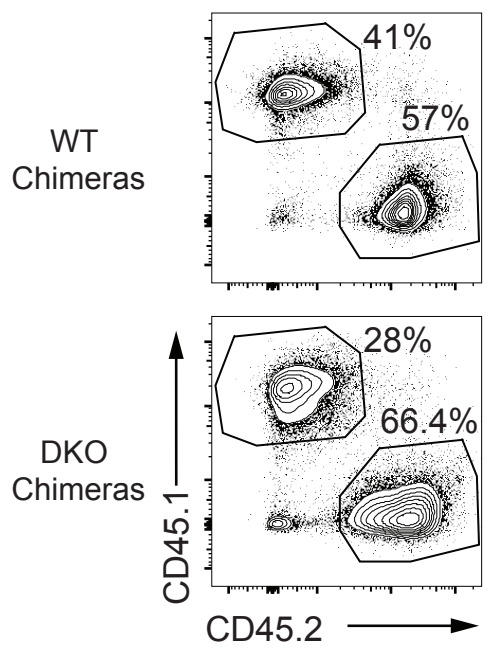
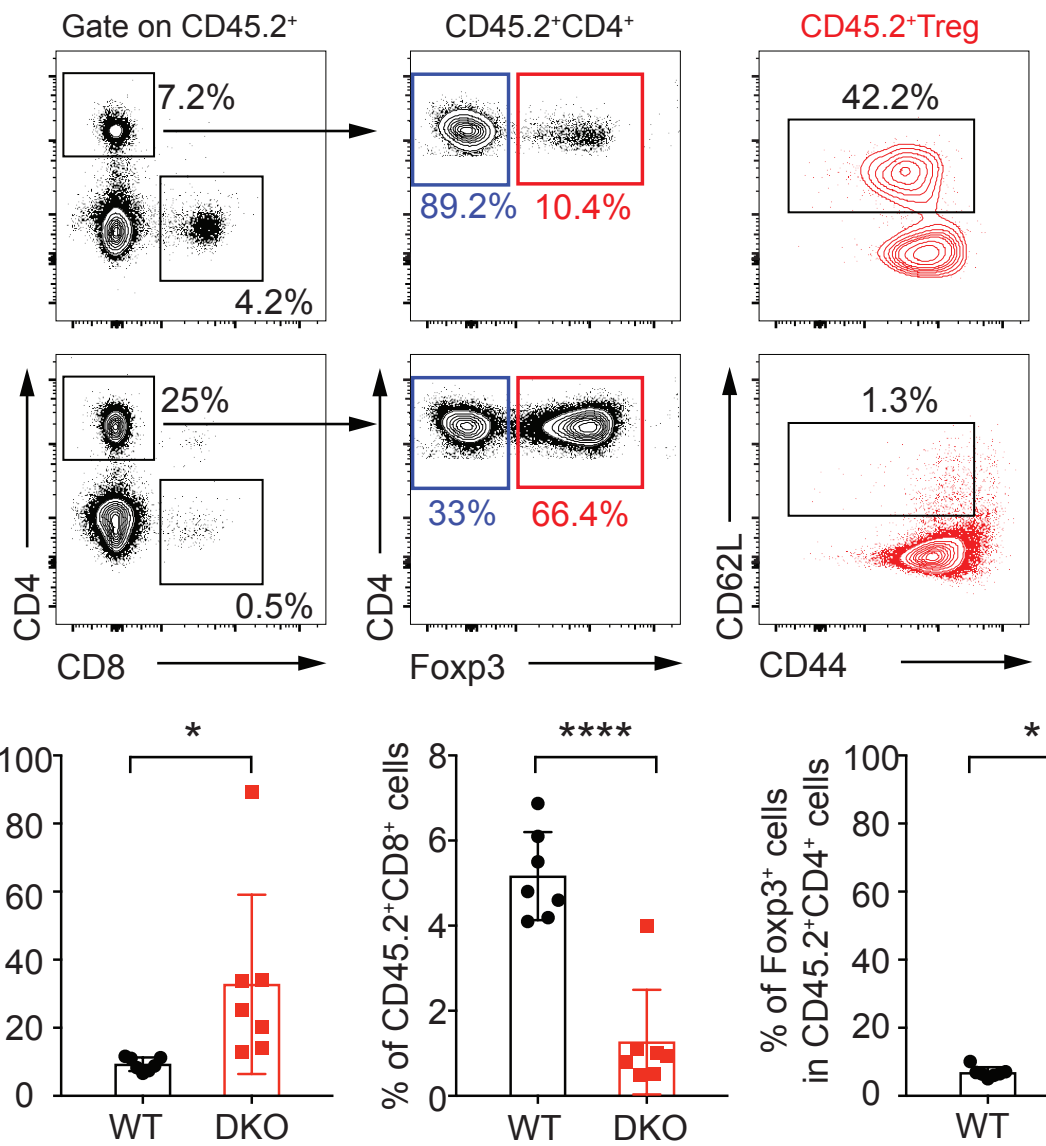

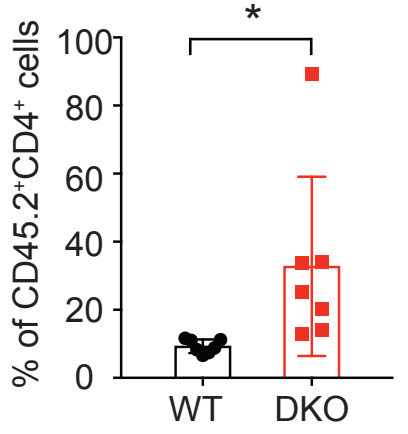

WT DKO
CD45.2 ${ }^{+}$Treg
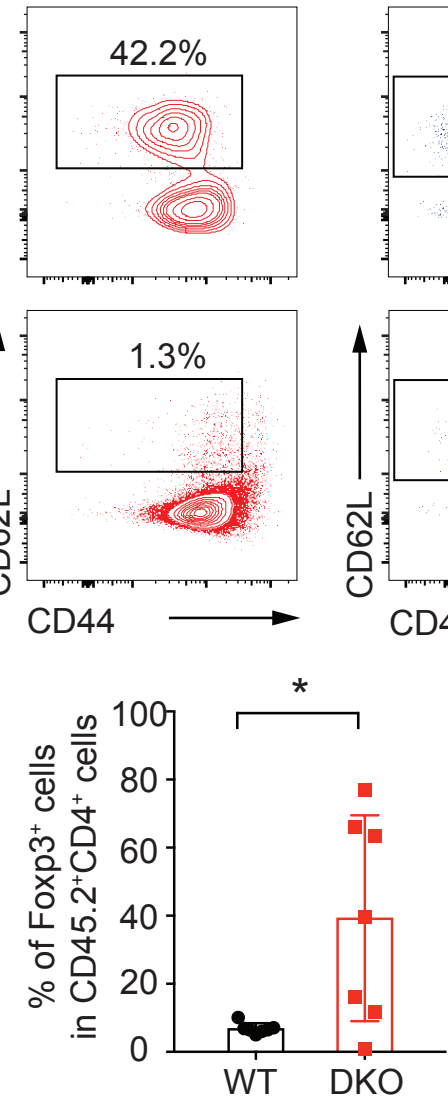

f

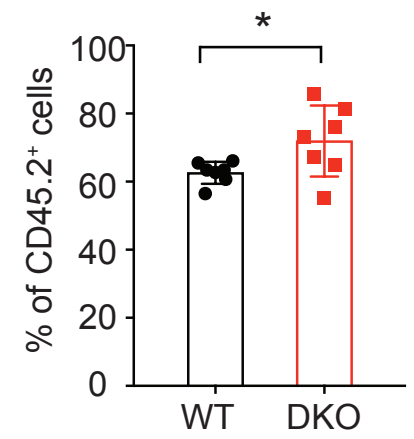

CD 45.2 $2^{+} \mathrm{CD} 4{ }^{+}$Foxp3
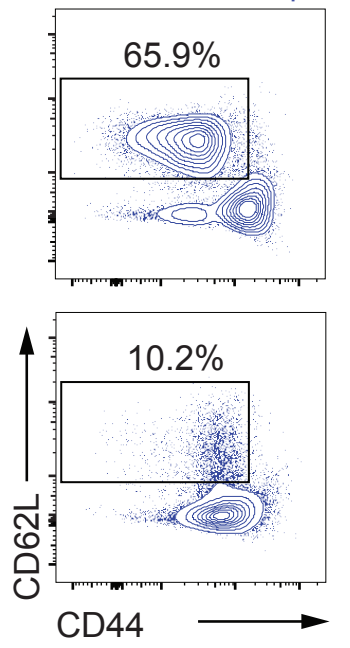


\section{Figure 6}

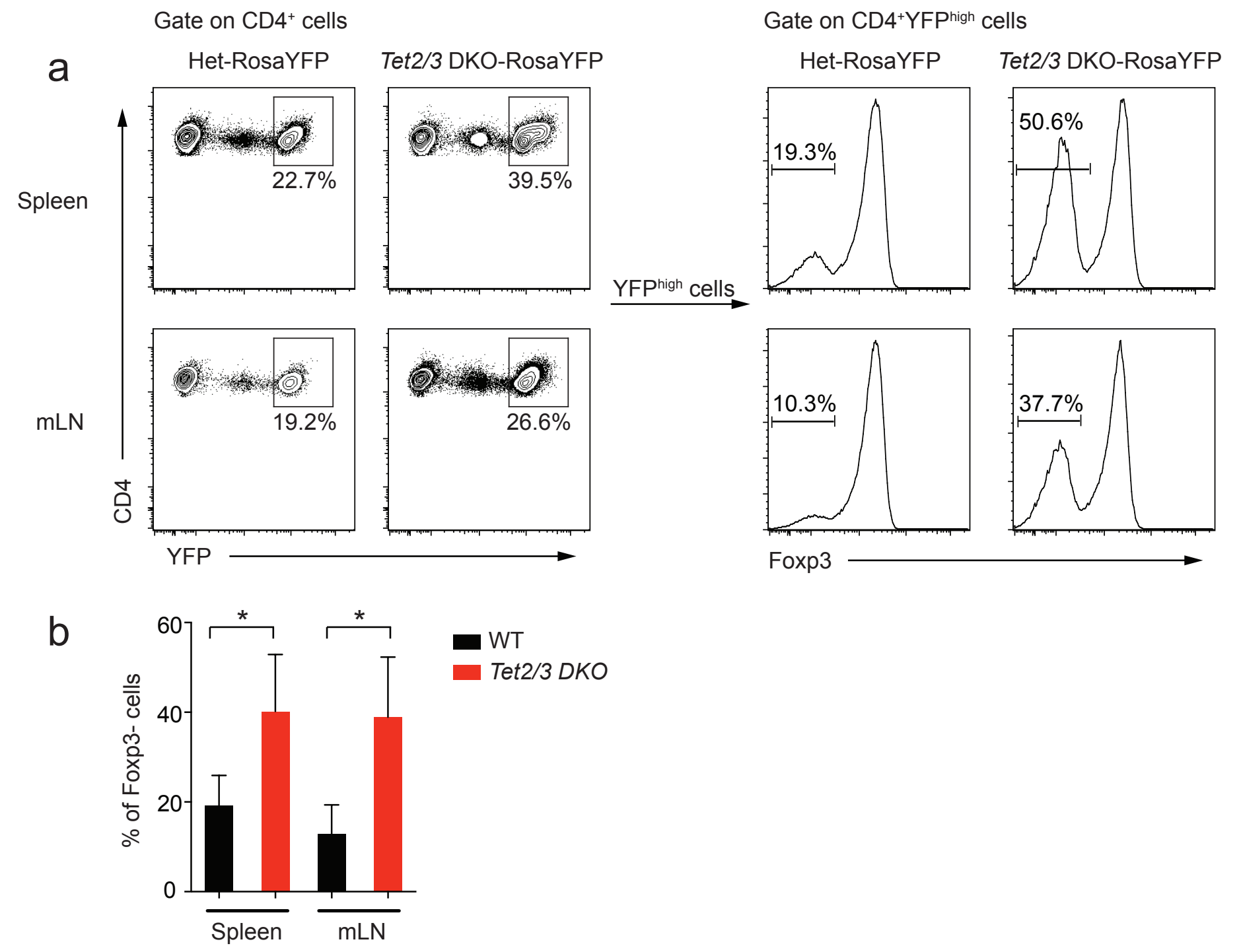


Figure 7

a

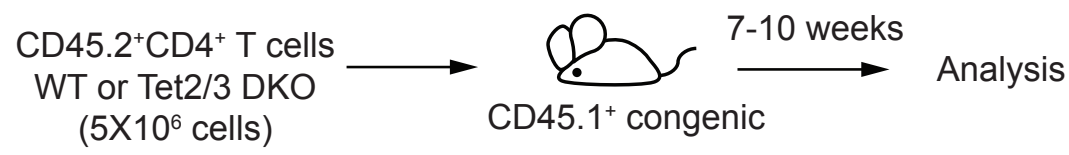

b

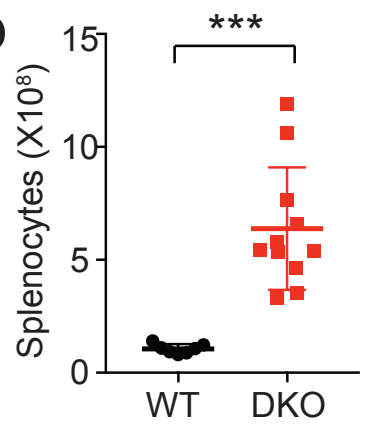

C

Mouse example1

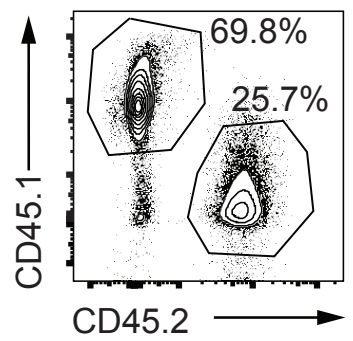

Mouse example2

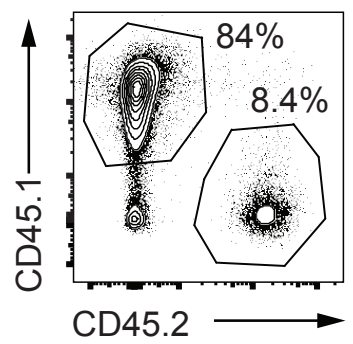

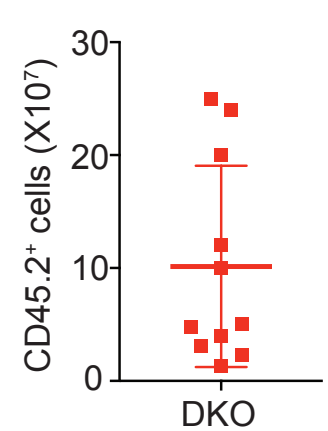
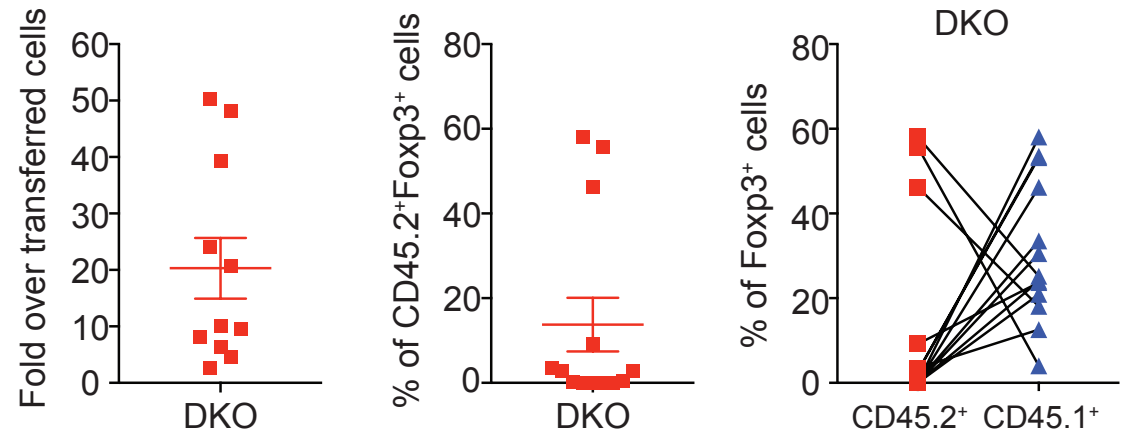

Host Cells

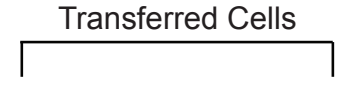

CD45.2+CD4+
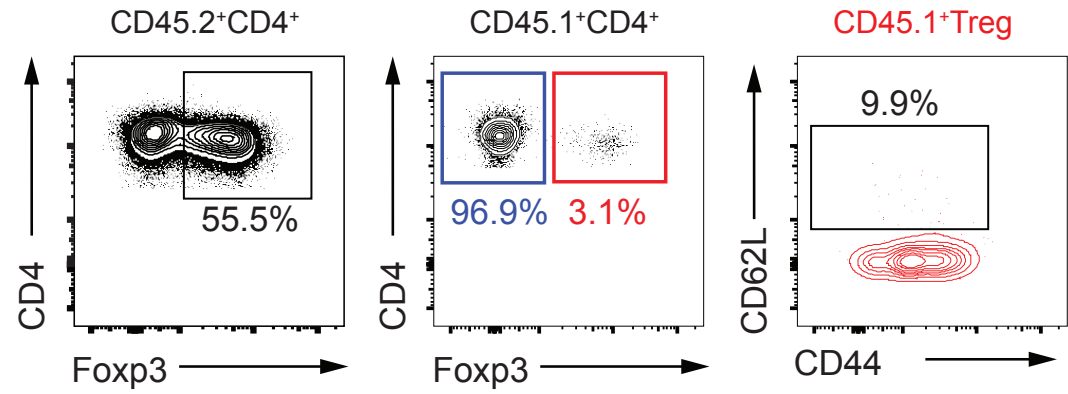

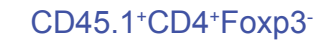

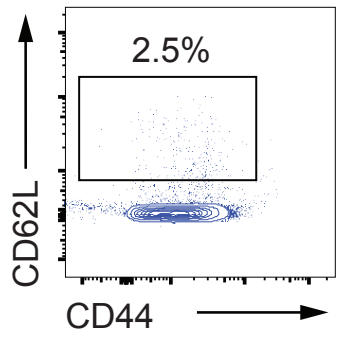

CD45.2+CD4 ${ }^{+}$

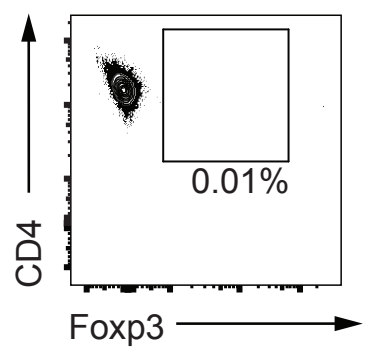

CD $45.1^{+}$CD $4^{+}$

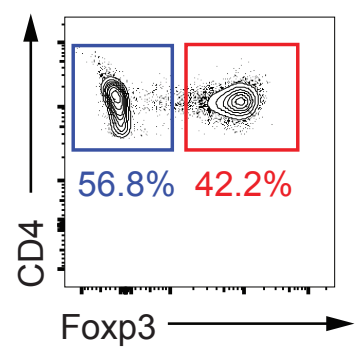

CD45.1+Treg

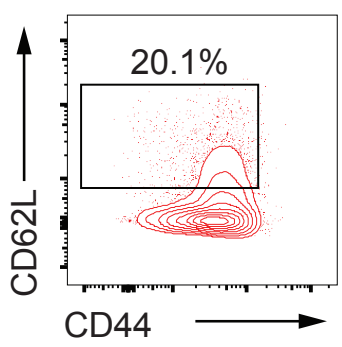

CD45.1 $1^{+}$CD4 ${ }^{+}$Foxp3

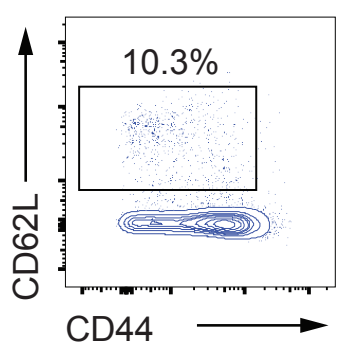

